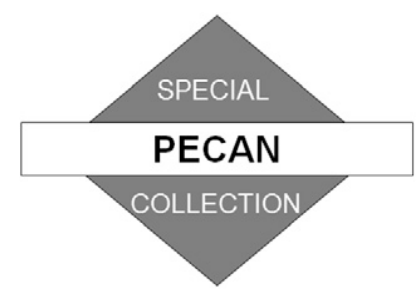

\title{
The Potential Role of Atmospheric Bores and Gravity Waves in the Initiation and Maintenance of Nocturnal Convection over the Southern Great Plains
}

\author{
David B. Parsons, Kevin R. Haghi, Kelton T. Halbert, and Blake Elmer \\ School of Meteorology, University of Oklahoma, Norman, Oklahoma
}

JUNHONG WANG

Department of Atmospheric and Environmental Sciences, University at Albany, State University of New York, Albany, New York

(Manuscript received 6 June 2017, in final form 15 June 2018)

\begin{abstract}
This investigation explores the relationship among bores, gravity waves, and convection within the nocturnal environment through the utilization of measurements taken during the International $\mathrm{H}_{2} \mathrm{O}$ Project (IHOP_2002) over the Southern Great Plains. The most favorable conditions for deep convection were found to occur within the boundary layer during the late afternoon and early evening hours in association with the diurnal cycle of solar insolation. At night, the layers most favorable for deep convection occur at and above the height of the nocturnal southerly low-level jet in association with distinct maxima in both the southerly and westerly components of the wind. Observations taken during the passage of 13 nocturnal wave disturbances over a comprehensive profiling site show the average maximum and net upward displacements with these waves were estimated to be $\sim 900$ and $\sim 660 \mathrm{~m}$, respectively. The lifting was not limited to the stable boundary layer, but reached into the conditionally unstable layers aloft. Since the net upward displacements persisted for many hours as the disturbances propagated away from the convection, areas well in excess of $10000 \mathrm{~km}^{2}$ are likely impacted by this ascent. This lifting can directly maintain existing convection and aid in the initiation of new convection by reducing the convective inhibition in the vicinity of the active convection. In agreement with past studies, strong ascent in the lowest $\sim 1.5 \mathrm{~km}$ was generally consistent with the passage of a bore. However, separate wave responses also occurred well above the bores, and low-frequency gravity waves may explain such disturbances.
\end{abstract}

\section{Introduction}

Haghi et al. (2017) recently showed that as the night progresses in the warm season over the Southern Great Plains, the interaction between convectively generated cold pools and the lower troposphere typically lies within a partially blocked flow regime, where bores will be generated. This study seeks to investigate the potential role of these bores in the initiation and maintenance of nocturnal convection. While high-resolution convection-permitting models show some promise, several studies (e.g., Davis et al. 2003; Clark et al. 2007; Surcel et al. 2010) have demonstrated that advancing forecast skill in numerical weather prediction models for these nocturnal systems has proven elusive. The low skill

Corresponding author: David B. Parsons, dparsons@ou.edu is important, since researchers have long established that summer thunderstorms and convective precipitation are most frequent after sunset over a broad region of the Great Plains, ranging from Oklahoma to southern Manitoba, and between about $92^{\circ}$ and $100^{\circ} \mathrm{W}$ (Kincer 1916; Wallace 1975; Easterling and Robinson 1985; Heideman and Fritsch 1988; Colman 1990a,b). Such nocturnal convective systems have public safety implications due to the presence of flash floods, high winds, hail, intense electrical storms, and even tornadoes (Maddox et al. 1979; Maddox 1980). The accurate representation of nocturnal convection in coarse-grid climate models is also particularly difficult (e.g., Bukovsky and Karoly 2009; Pritchard et al. 2011).

Several studies (e.g., Carbone et al. 2002; Davis et al. 2003; Ahijevych et al. 2004; Tuttle and Davis 2006; Parker and Ahijevych 2007; Carbone and Tuttle 2008) 
have shown that this nocturnal maximum in convection is part of a larger-scale, time-space envelope of precipitation that often originates near or to the east of the Rocky Mountains and subsequently propagates eastward across the eastern two-thirds of the United States. These episodes of coherent rainfall patterns are most frequently observed under "weakly forced" conditions, with an upscale growth beginning during the evening and reaching a maximum extent after midnight.

Significant attention has been paid to the question of how these propagating envelopes of convection are maintained in this nocturnal environment (e.g., Li and Smith 2010; Geerts et al. 2017). The environment typically includes a nocturnal low-level jet (NLLJ) that transports warm, moist air northward above the stable nocturnal boundary layer (e.g., Means 1952; Curtis and Panofsky 1958; Pitchford and London 1962; Maddox et al. 1979; Trier and Parsons 1993). The intensity of the NLLJ tends to be correlated with heavier rainfall (e.g., Arritt et al. 1997; Tuttle and Davis 2006). The stable boundary layer complicates the convective dynamics, as the typical framework (e.g., Rotunno et al. 1988) for explaining the upscale growth and maintenance of convection as cold outflows generated by storms spread and lift a well-mixed boundary layer to its level of free convection (LFC) may not be directly applicable.

The role of bores in the rejuvenation of nocturnal convection was noted by Carbone et al. (1990) and Crook et al. (1990). In addition, Karyampudi et al. (1995), Locatelli et al. (2002), and Wilson and Roberts (2006) found that bores could initiate convection. Parker (2008) and French and Parker (2010) utilized idealized numerical simulations to explore the evolution of nocturnal squall lines within the presence of increasing boundary layer stability. As the stability increased in their simulations, the speed of the cold pool slowed due to decreases in the buoyancy difference between the cold pool and the ambient environment. Convection in this "stalling phase" continued to be fed by surface/boundary layer air lifted by the cold pool. As the stability continued to increase, the squall line evolved into an elevated convective system supported by a bore.

Numerous observational studies (Weckwerth et al. 2004; Whiteman et al. 2006; Knupp 2006; Wilson and Roberts 2006; Koch et al. 2008a,b; Tanamachi et al. 2008; Martin and Johnson 2008; Hartung et al. 2010; Coleman et al. 2010; Coleman and Knupp 2011; Marsham et al. 2011) have revealed that bores are generated by nocturnal convection. With the exception of Wilson and Roberts (2006), these investigations have been case studies. In an effort to move beyond the case study approach, Haghi et al. (2017) undertook a systematic investigation into the dynamical relationship among density currents, bores, and the nocturnal environment utilizing observations taken during the International $\mathrm{H}_{2} \mathrm{O}$ Project (IHOP_2002; Weckwerth et al. 2004). Through an application of a variant of hydraulic theory, Haghi et al. (2017) were able to show that as the night progressed, the interaction between convective outflows and the nocturnal environment tended to increasingly fall within a partially blocked flow regime where atmospheric bores would be generated. This finding was supported by observational analysis utilizing surface meteorological observations and radar "fine lines" that revealed that most convective outflows generated bores. Our investigation utilizes data also taken from IHOP_2002 to explore the vertical structure of bores and their potential to initiate and maintain deep convection. A key finding of this study that was not expected from hydraulic and linear wave theory of bores was that additional wave disturbances extend over the lower troposphere. Such features varied significantly in structure between the different cases and sometimes appeared consistent with the expectation from past work on long-period gravity waves (e.g., Nicholls et al. 1991; Pandya et al. 1993; Mapes 1993; Pandya and Durran 1996; Lane and Reeder 2001; Fovell 2002; Adams-Selin and Johnson 2013; Stephan et al. 2016).

\section{Dataset and methodology}

IHOP_2002 took place from 13 May to 25 June 2002 (Weckwerth et al. 2004; Weckwerth and Parsons 2006). Since the large-scale conditions generally suppressed convection during the early portions of the experiment, we focused on convection events that took place between 2 and 25 June 2002. A focal point of our study is composites constructed from 3-hourly soundings taken from five sites over a 30-day period in association with the Department of Energy's Atmospheric Radiation Measurement (ARM) Program (e.g., Stokes and Schwartz 1994; Mather and Voyles 2013). This sounding array is located within the region with a nocturnal convective maximum (Fig. 1a) so that the composited vertical profiles of CAPE, CIN, and horizontal winds allow insight into both bores and the nocturnal convective maximum. Given that nocturnal convection can be elevated and fed by CAPE above the stable boundary layer [see Geerts et al. (2017) and references within], the use of the vertical profile of CAPE and CIN provides greater insight into the relationship between convection and the environment than can be obtained from a reliance on surface properties alone.

This investigation also utilized data from the Multiple Antenna Profiling Radar (MAPR) system deployed at 

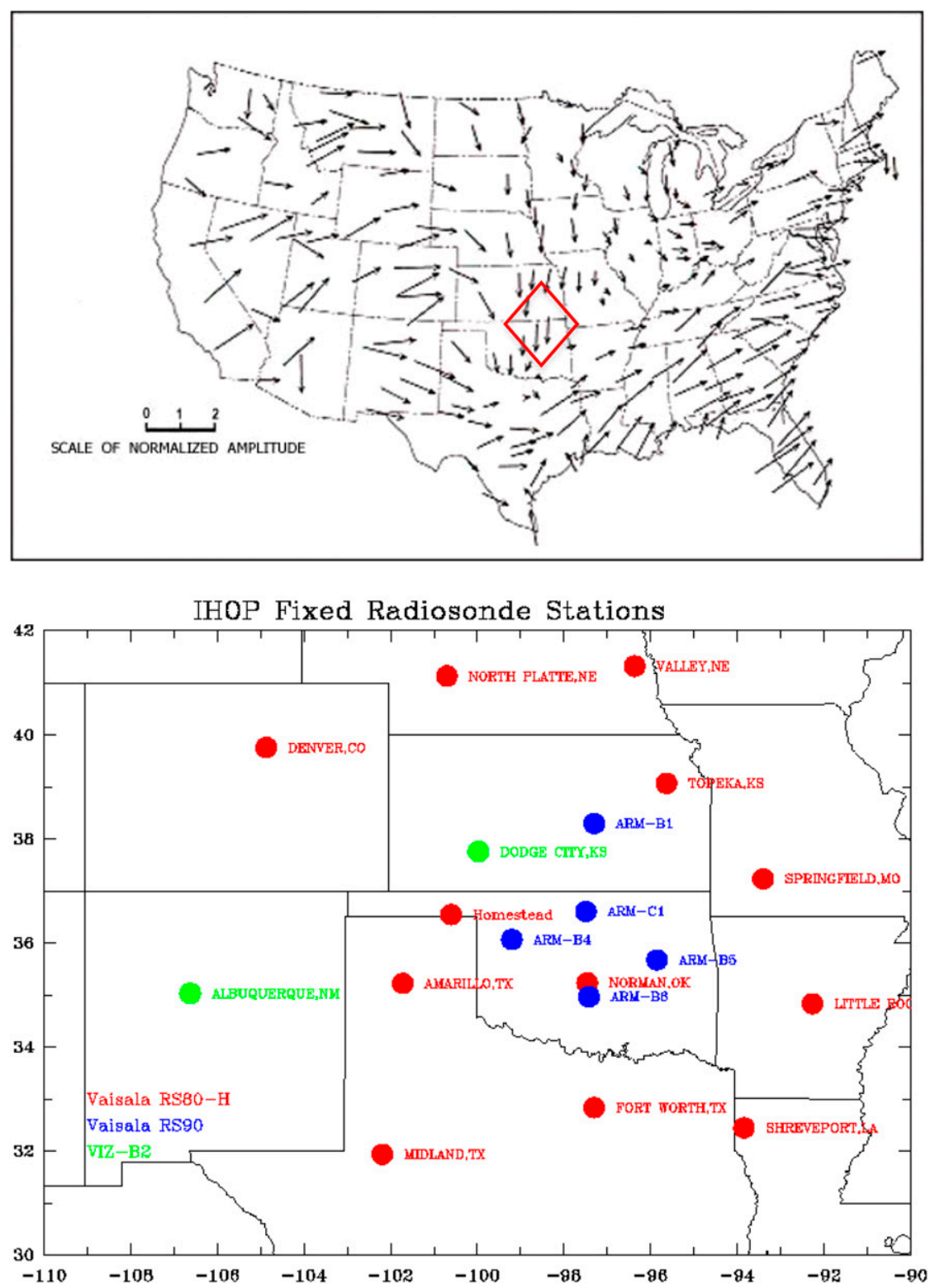

FIG. 1. (top) The approximate location of the sounding domain for the ARM sites relative to the diurnal variations in warm-season thunderstorm activity. The diurnal variations were taken from Wallace and Hobbs (1977), with the length of the vector indicating the amplitude of the diurnal cycle and the direction of the vector indicating the time of day (e.g., eastward pointing is an 1800 local time maximum and southward pointing is a midnight maximum). The sounding network is located within a region with a maximum in thunderstorm activity near midnight. (bottom) The radiosonde network and radiosonde type for IHOP_2002 consisting of the sites associated with the National Weather Service (indicated with station name and launching Vaisala RS8-H or VIZ-BZ sondes), five sites maintained by the Department of Energy's ARM Program, and IHOP_2002's Homestead site in the Oklahoma Panhandle, which was collocated with an extensive collection of surface and profiling instrumentation.

the "Homestead" site in western Oklahoma (Fig. 1b) as part of NCAR's Integrated Sounding System (ISS; Parsons et al. 1994). MAPR is a spaced antenna 915-MHz wind profiler that simultaneously determines the horizontal winds and vertical motions along with the backscatter power expressed as a single-to-noise ratio from a single vertically pointing radar beam (Cohn et al. 2001). In the absence of precipitation, these vertical 


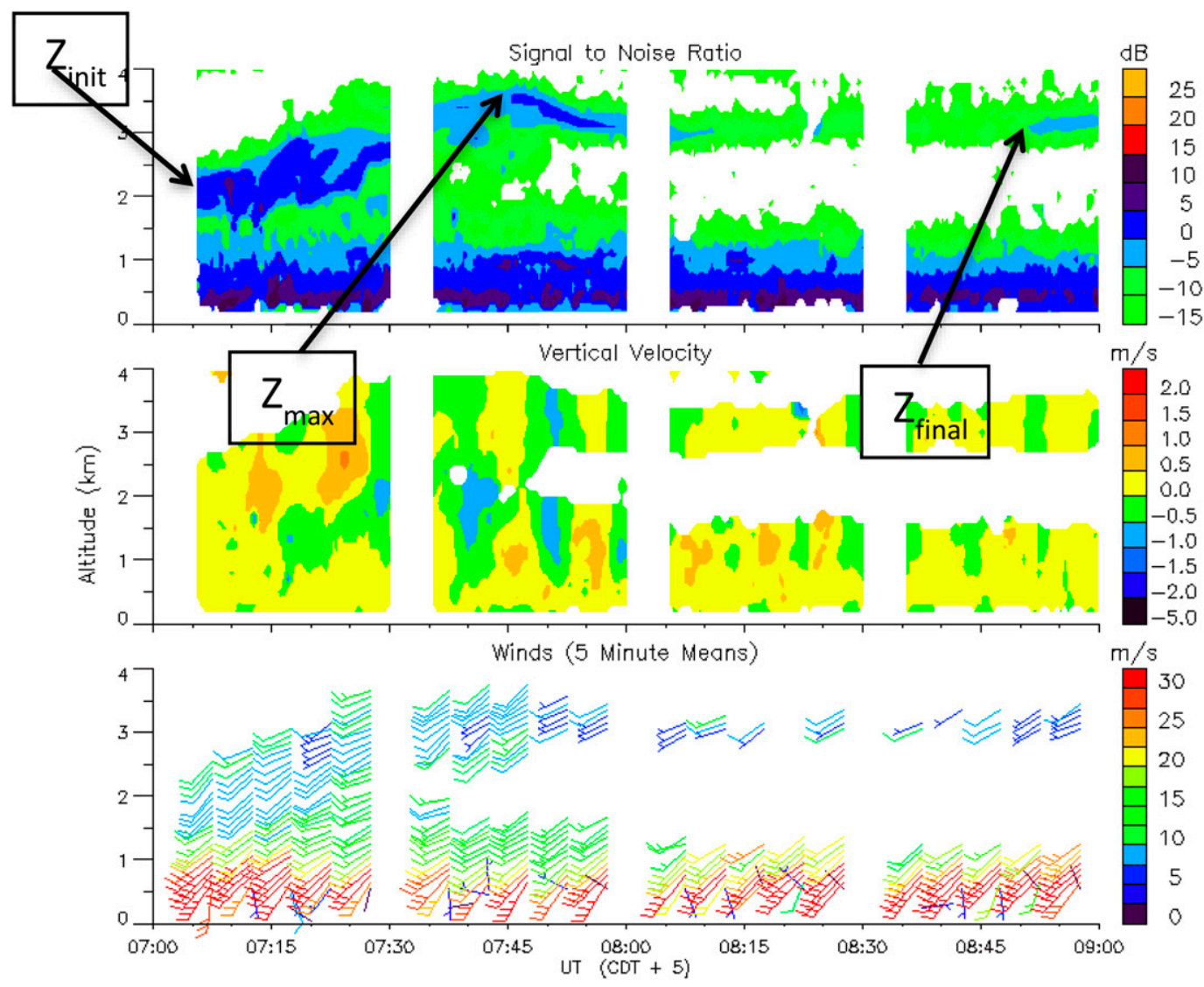

FIG. 2. An example of the determination of the displacement of a scattering layer utilizing the vertically pointing MAPR datasets taken from the IHOP_2002 Homestead site on 2 Jun 2002. The initial position of the layer $Z_{\text {init }}$, the maximum height $Z_{\max }$, and the final position of the layer $Z_{\text {final }}$ as determined by the changes in time in the signal-to-noise field are shown in the top panel. Note some ground clutter is suggested by the light winds in the vertical layer containing the LLJ.

motions correspond to the vertical air motion with the complication that the measurements can also be impacted by insects, which tend to oppose the vertical motion that introduces a negative bias in the measurements of upward velocity (e.g., Geerts and Miao 2005; Knupp et al. 2016).

In contrast to the oscillations associated with gravity waves, a net upward displacement of air is a defining characteristic of a bore disturbance [e.g., see Figs. 3 and 7 of Rottman and Simpson (1989)]. To understand the potential role that these displacements may play in maintaining a nocturnal convection system over the plains, we estimated the maximum and the net upward vertical displacements of the scattering layers measured by MAPR (Fig. 2) that took place with the passage of a bore. These scattering layers are associated with changes in the refractive index, the Brunt-Väisälä frequency squared, and/or the turbulent energy dissipation rate. Comparisons between profiling and sounding measurements have shown that vertical gradients of water vapor dominate the changes in the refractive index in the lowest $10 \mathrm{~km}$ of the atmosphere, followed by gradients in temperature (e.g., Tsuda et al. 2001). Thus, on average, the well-defined layers of enhanced backscatter in nonsaturated regions are likely layers with enhanced vertical gradients of water vapor and perhaps temperature. Since the refractive index can be expressed in terms of potential temperature and specific humidity (e.g., Stankov et al. 2003), the regions of enhanced scattering will remain nearly constant and certainly clearly evident for dry adiabatic ascent or descent. Whether the layer becomes saturated is not a first-order issue unless precipitation forms and overwhelms the signal, since we are not interested in the exact value of the backscatter, rather just in whether a layer of enhanced signal to noise is maintained in time. In the case of falling precipitation, the enhanced power return and the large downward velocities are easily detectable.

Thus, the overall estimation of the changes in height of a time-continuous layer of backscatter, as implied by 
observations of the signal-to-noise ratio, is not subject to any restrictive assumptions on the nature of the scatterers. However, we do infer that changes in the height of the layer are due to lifting or subsidence by the bore or gravity wave disturbance. This assumption is generally supported by the general correlation of vertical motions with changes in the height of the scattering layers (e.g., Figs. 2, 7, 9). The general correlation of vertical motions measured by MARP with the upward displacement of scattering layers is also evident in previous studies in the literature, including Figs. 4 and 6 of Koch et al. (2008b) and Fig. 14 of Haghi et al. (2017). Note that we are not assuming that the lifting represents the local displacement by the disturbance, but rather an accumulated lifting by disturbance. In the interpretation of our results, the reader should be aware that the derived displacement heights are subject to this assumption.

This method of inferring ascent from displacement of scattering layers was used, since the upward displacements could not be obtained from integrating the vertical air motions over time, as the MAPR wind measurements were interrupted with $5 \mathrm{~min}$ of radio acoustic sounding system measurements (e.g., Riddle et al. 1996) every $30 \mathrm{~min}$. In addition, as stated earlier, the upward motions have been shown to have a negative bias due to opposing flight of insects (e.g., Geerts and Miao 2005; Knupp et al. 2016). Indeed, attempts to use the vertical motions tended to underestimate the observed displacements. The vertical motions are also subject to errors due to birds, aircraft, and ground clutter, which was a problem at this site in IHOP_2002 in during periods of high winds associated with the low-level jet.

Layer displacements were also estimated from the reflectivity measured by the vertically pointing S-band frequency-modulated continuous wave (FM-CW) radar (e.g., Weckwerth et al. 2004; Koch et al. 2008b), which proved particularly useful during periods of high surface winds when the MAPR observations were plagued by ground clutter contamination in the lowest few hundred meters. Displacement heights from the FM-CW system were estimated to the nearest $100 \mathrm{~m}$ in 5-min increments to match the resolution of MAPR. The FM-CW radar was only available until 17 June. Data from surface meteorological station and radiosondes at Homestead complemented the MAPR and FM-CW measurements. Unfortunately, nocturnal radiosonde launches at this site were limited to a few events.

\section{Diurnal variations in convective instability and winds}

A composite diurnal cycle of vertical profiles of CAPE, CIN, and zonal $(u)$ and meridional $(v)$ winds was constructed from the 3-h soundings for days when the winds below $1 \mathrm{~km}$ contained a southerly component in excess of $15 \mathrm{~m} \mathrm{~s}^{-1}$ (Fig. 3). The CAPE and CIN composites reveal that this early summer environment is similar to the springtime severe storm conditions (e.g., Carlson et al. 1983), with the most favorable conditions for deep convection occurring in the boundary layer during the afternoon and early evening (Fig. 3). After midnight, a secondary maximum in CAPE develops, with the peak value at a height of $\sim 500 \mathrm{~m}$ between 0400 and 0500 LST (LST $=$ UTC $-6 \mathrm{~h}$ ). The timing and height of this secondary CAPE maximum corresponds relatively closely to the peak southerly component of the NLLJ at a height of $\sim 600 \mathrm{~m}$ (Fig. 3). As stated earlier, past studies have linked the advection of warm, moist air by the southerly NLLJ to the creation of favorable conditions for nocturnal convection. The nocturnal peak in CAPE associated with the jet is relatively weak and perhaps "smoothed out" in our compositing technique, since simulations of nocturnal convective systems (e.g., Blake et al. 2017) have shown that the corridors of large CAPE and reduced CIN aloft can be relatively narrow (e.g., $\sim 200 \mathrm{~km}$ ).

Above this southerly NLLJ, the CAPE is still large $\left(\sim 1000 \mathrm{~J} \mathrm{~kg}^{-1}\right)$, but the CIN begins to fall off rapidly with height near the $0.6-\mathrm{km}$ layer (Fig. 3), producing a layer that is quite favorable for deep convection. This low-CIN layer corresponds to a layer of westerly winds that reaches a peak value before sunrise at a height of $\sim 1 \mathrm{~km}$ (Fig. 3). The relationship between the southerly and westerly flows and the CAPE and CIN profiles suggests the likely importance of differential advection. Specifically, the strong southerly component of NLLJ advects warm, moist air northward, while the elevated westerly maximum advects air from over the higher terrain to the west. Depending on the origin and subsequent trajectory of this westerly flow, the air can be from a deep, dry, well-mixed boundary layer to the west of the dryline or from upper portions of the moist boundary layer to the east of the dryline. Ongoing analysis of the characteristics of this westerly flow (Rattray et al. 2018) suggests that the stability in this layer varies significantly, both spatially and from case to case.

During the day, an intensifying upslope flow is evident at $\sim 1200$ LST, with the strongest flow at $\sim 1830$ LST. Upslope flow (negative $u$ component in Fig. 3c) to the east of the dryline in response to differential heating on the sloping terrain has been noted in simulations (e.g., Sun and Ogura 1979) and observations (Parsons et al. 1991). The upslope winds, however, can also be enhanced by frictional turning of the southerly flow. The observed diurnal variations in both components of the winds are expected from the recent study by Shapiro et al. (2016) 

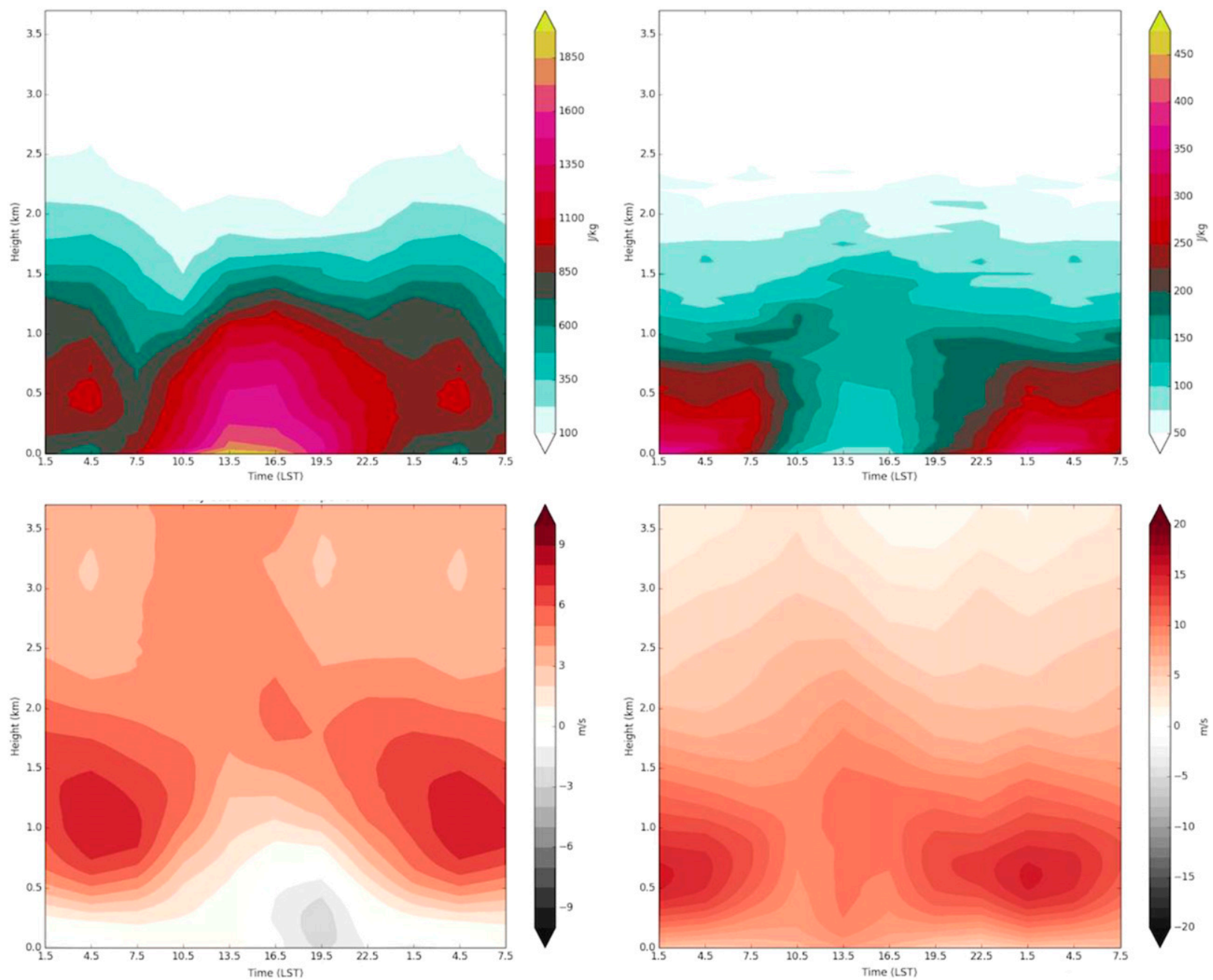

FIG. 3. A composite of the diurnal variations in stability and winds as a function of height as constructed from 3-hourly ARM radiosonde dataset taken during IHOP_2002. The time is in LST with units of hours. (a) CAPE and (b) CIN are shown in color contours with units of $\mathrm{J} \mathrm{kg}^{-1}$. (c) Zonal wind speed and (d) meridional wind speed are shown with units of $\mathrm{m} \mathrm{s}^{-1}$.

that mathematically unified the inertial oscillation in the ageostrophic component of the NLLJ (Blackadar 1957) with diurnal variations in thermal forcing over sloped terrain (Holton 1967).

One difference between Shapiro et al.'s results and the observations in this work is that the observed nocturnal variations in the westerly winds extend throughout the lower troposphere with a minimum between $\sim 3$ and $3.5 \mathrm{~km}$ (Fig. 3). A minimum in the downslope winds above the maximum suggests the possibility of a return flow developing aloft, as can occur in response to differential cooling (land breeze) or cooling on sloped terrain (valley flow). Such a return flow cannot develop in Shapiro et al.'s (2016) approach, since the boundary conditions dictate that the $u$ component of the wind far above the slope must vanish. Another difference is that
Shapiro et al. found both the nocturnal westerly and southerly wind maxima descend with time to a greater degree than in the observations (see our Fig. 3 and their Fig. 5). These difference may be due to the prescription of a height-invariant turbulent diffusion coefficient in the Shapiro et al. study.

The finding that conditions are more favorable for convection over the Great Plains during the day is counterintuitive, given that the region has a nocturnal maximum in convective activity. Various mechanisms have been proposed to produce upward motion over the plains at night, leading to an environment more susceptible to deep convection. Such proposed mechanisms include (i) ascent driven by the NLLJ (e.g., Means 1952; Pitchford and London 1962; Hering and Borden 1962; Bonner 1968; Paegle 1978; Pu and Dickinson 2014; 
Shapiro et al. 2018); (ii) pressure tides (Dai et al. 1999); (iii) propagating gravity waves generated by elevated terrain to the west (e.g., Tripoli and Cotton 1989a,b; Carbone and Tuttle 2008); (iv) ascent in association with eastward-moving potential vorticity anomalies (e.g., $\mathrm{Li}$ and Smith 2010); and (v) the NLLJ overrunning a quasistationary east-west stationary front (Trier and Parsons 1993). The interest in these mechanisms lies in the inherent implication that ascent at night makes the environment more favorable for deep convection, which should presumably be reflected by a reduction in CIN as parcels are brought closer to their LFC and perhaps an increase in CAPE from layer lifting. Given that the observed conditions (Fig. 3) for convection are less favorable at night than during the day (with the exception of the lower CIN above $\sim 1 \mathrm{~km}$ during the night), the ascent associated with these mechanisms is evidently not sufficient to produce a nocturnal environment more susceptible to deep convection than found during the afternoon and early evening. The ascent could, however, be intermittent in time and/or limited in spatial extent so that the impacts are not evident in our compositing technique. Still, the observations raise the possibility that the explanation for the nocturnal maximum in deep convection over the Great Plains may lie in positive feedbacks between nocturnal convection and the environment, as proposed by Heideman and Fritsch (1988).

\section{Cold pools, bores, and the nocturnal environment}

\section{a. Review of the generation of bores in the IHOP_2002 dataset}

The potential positive feedback that will be investigated in our study is when convection generates bores and the lifting by these bores subsequently creates conditions more favorable for the initiation and maintenance of deep convection. Such lifting is also important since the changes in the winds and thermodynamics can also impact the structure and evolution of convection. We will start by reviewing the findings of Haghi et al. (2017), who essentially applied a variant of hydraulic theory to flow over orography, but with density currents treated as a proxy for orography (Koch et al. 1991). The environment is treated as in a two-layer, two-dimensional, inviscid flow, similar to those studied by Long (1954), Houghton and Kasahara (1968), Baines (1984), and Rottman and Simpson (1989), with the lower layer representing the stable nocturnal boundary layer, while the second layer is neutral and infinitely deep. The flow regimes can be characterized by a Froude number (Fr) and a nondimensional height $H{ }^{1}$ given by

$$
\begin{aligned}
& \mathrm{Fr}=\frac{U_{\mathrm{inv}}-C_{\mathrm{dc}}}{\sqrt{g \frac{\Delta \theta}{\theta_{\mathrm{vw} \_\mathrm{inv}}} h_{o}}}, \\
& H=\frac{d_{o}}{h_{o}} .
\end{aligned}
$$

Specifically, Fr was calculated from the ratio of the density current-relative flow speed $\left(U_{\mathrm{inv}}-C_{\mathrm{dc}}\right)$ to the environmental gravity wave speed $\sqrt{g\left[\Delta \theta /\left(\theta_{\mathrm{vw} \_ \text {inv }}\right)\right] h_{o}}$, with $C_{\mathrm{dc}}$ the speed of the density current, $H$ the ratio of the depth of the density current, and $d_{o}$ the depth of the surface inversion layer $h_{o}$. In this system, $U_{\mathrm{inv}}$ is the vertically averaged ground-relative environmental wind in the inversion layer, $g$ is the acceleration due to gravity, $\Delta \theta$ is the change in potential temperature across the inversion between the two layers, and $\theta_{\mathrm{vw} \_ \text {inv }}$ is the mean virtual potential temperature of the lower layers.

The resulting flow regimes within the $\mathrm{Fr}$ and $H$ parameter space for air flowing over a density current are shown in Fig. 4. These flow regimes include a supercritical (region a in Fig. 4) and subcritical flow (region d in Fig. 4). The partially and completely blocked flow regimes (regions $\mathrm{b}$ and $\mathrm{c}$, respectively) occur when a semipermanent rise (i.e., a bore) forms in the inversion layer ahead of the density current (Fig. 4). Without an energy loss, the bore would continue to expand horizontally for as long as the environmental flow remains partially or completely blocked (Carbone et al. 1990; Wakimoto and Kingsmill 1995; Koch and Clark 1999). The height of the bore can also be determined in an $\mathrm{Fr}-H$ parameter space. In the region between supercritical and partially blocked flow, and for large-amplitude bores, disturbances that take on the characteristics of a density current are termed a type $\mathrm{C}$ bore (e.g., Rottman and Simpson 1989; Fig. 4).

Haghi et al. (2017) utilized the IHOP_2002 dataset to determine the most likely outcomes from the interaction between the observed cold pool and the nocturnal environment as a function of time. Their study employed bootstrap resampling of both the convectively generated cold pools and the nocturnal environment to establish probability densities in a flow regime diagram (Fig. 5) to determine the most likely flow regimes. One inference

\footnotetext{
${ }^{1}$ As in Haghi et al. (2017), the Fr and $H$ given here are equivalent to $F_{o}$ and $D_{o}$ in Rottman and Simpson (1989).
} 


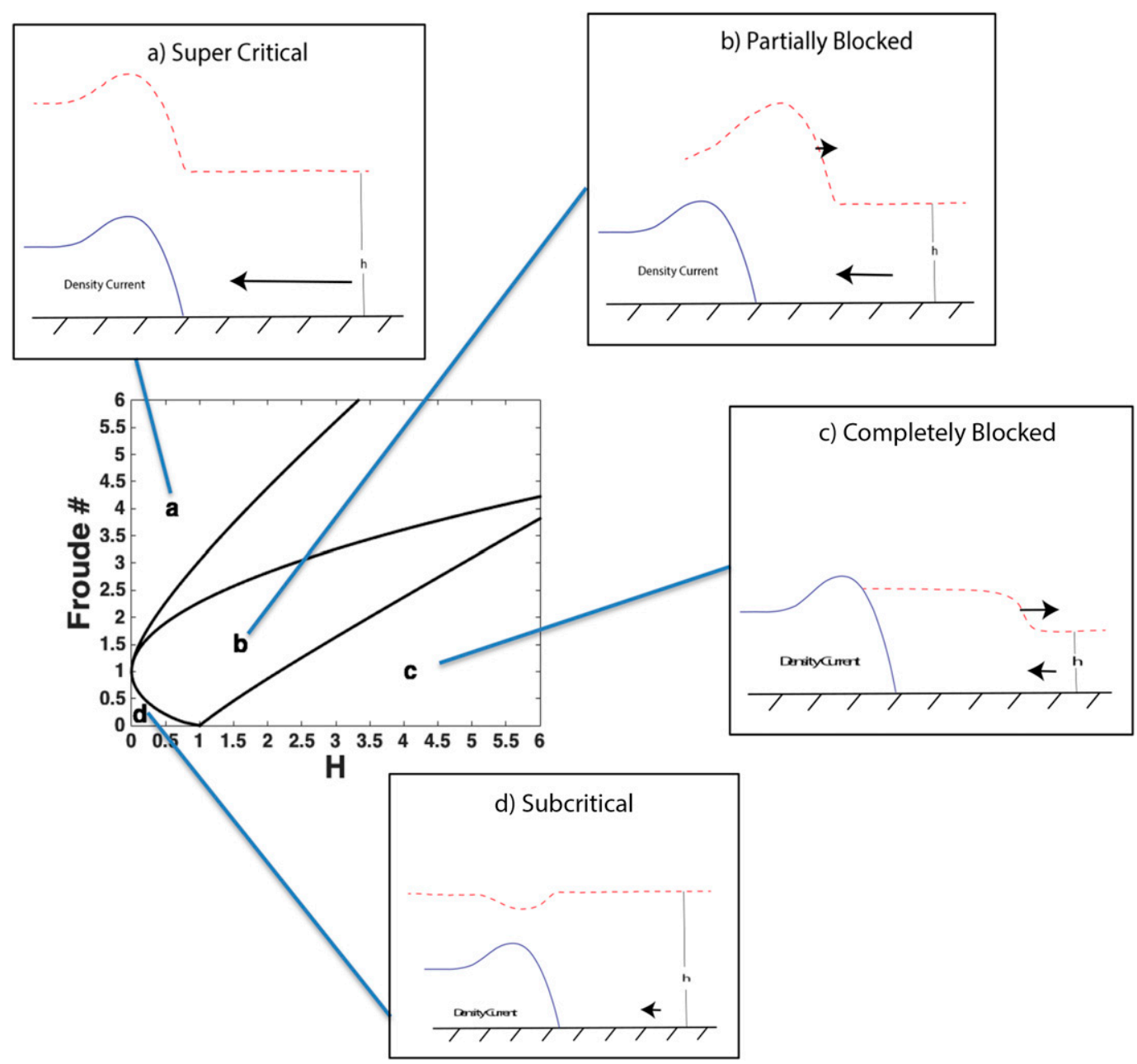

FIG. 4. The flow regimes for two-layer flow over a streamlined obstacle with the upper layer of infinite depth. The schematic is a modification of the diagrams of Baines and Davies (1980) and Rottman and Simpson (1989) with the obstacle represented by a density current. The area defined by the two lines between regimes a and $b$ defines a regime where the flow is either supercritical or partially blocked. Type $\mathrm{C}$ bores can occur in this region and in the higher-Fr regions of regime $b$.

to be drawn from the Haghi et al. (2017) analysis (Fig. 5) is that during the night (e.g., 2100-0600 LST), the center of the highest probability densities lies in the partially blocked regime, suggesting that convectively generated cold pools will most likely trigger bores. The distributions change throughout the night so that at 2100 LST, for example, the highest densities of occurrence are centered within the partially blocked regime, but quite close to the blocked regime. The distribution at this time is also quite broad so that type $\mathrm{C}$ bores may also occur. As the night progresses to 0300 LST, the distribution contracts more and more toward flows lying within the partially blocked regime (Fig. 5). Hence, after 0300 LST, the likely flow regime falls well outside of the region of the regime where type $\mathrm{C}$ bores occur (Fig. 5).

\section{b. Comparison with the Parker (2008) and French and Parker (2010) simulations}

The idealized simulations in the pioneering studies by Parker (2008) and French and Parker (2010) provide a useful framework for interpreting the evolution of squall lines in the presence of a stabilizing boundary layer. Differences exist, however, between the observations taken during IHOP_2002 and the simulations that impact the predicted flow regimes. One difference is the speed of the density currents. The theoretical cold pool speeds in the idealized simulations [see Fig. 7 in Parker (2008)] were estimated to range from 20 to $30 \mathrm{~m} \mathrm{~s}^{-1}$. In contrast, the median value for the speed of the observed cold pools was $11 \mathrm{~m} \mathrm{~s}^{-1}$, with only 1 of 48 observed cold pools having a speed that exceeded $20 \mathrm{~m} \mathrm{~s}^{-1}$ and only 

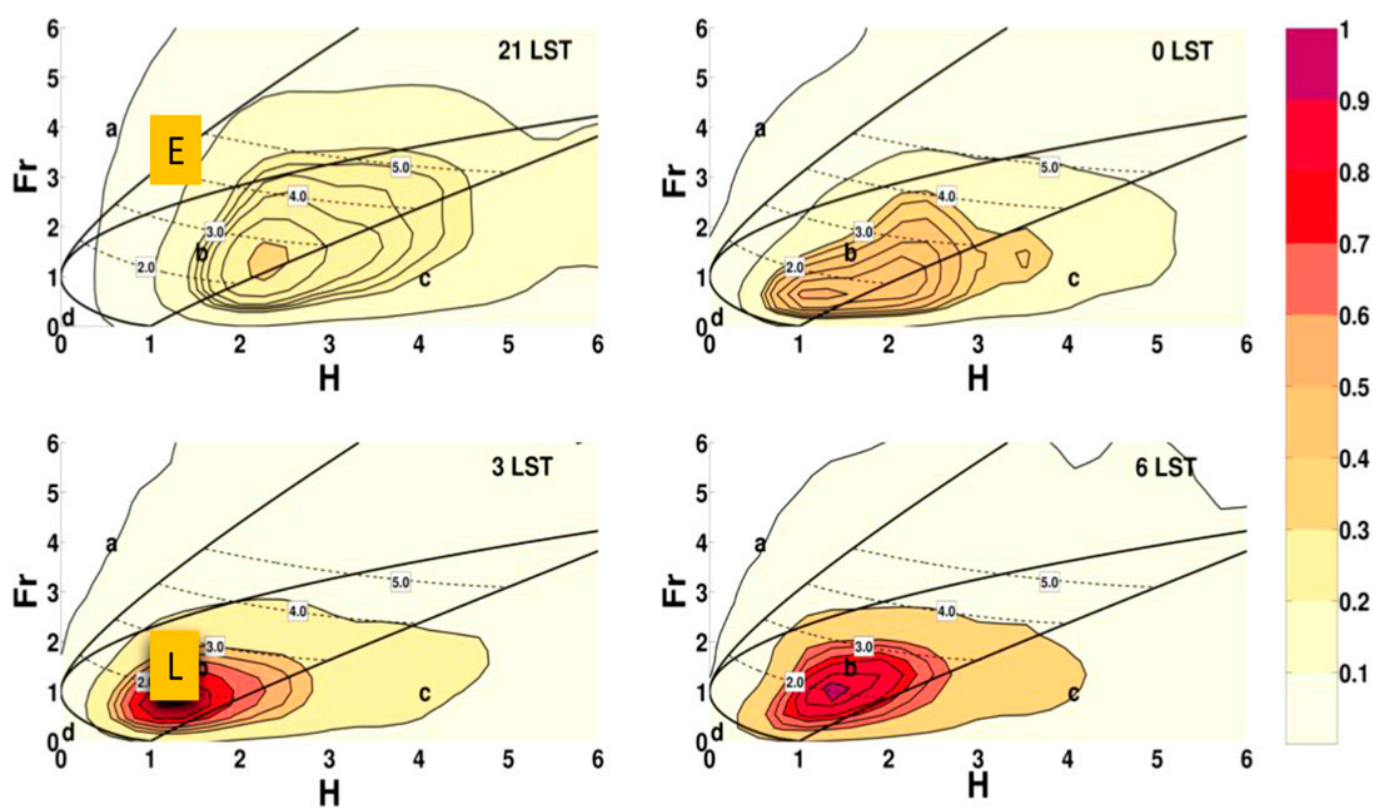

FIG. 5. Contours of the 95th, 50th, 25th, 20th, 15th, 10th, and 5th percentiles of the densest points in the 2D density estimate as a function of time. Color fills within contours represent the magnitude of the $2 \mathrm{D}$ density estimate normalized by the densest value among all four panels: (a) 2100, (b) 0000, (c) 0300, and (d) 0600 LST. The "E" denotes the estimate of flow regime early in Parker's (2008) simulation, while "L" denotes the estimate from the later stage. The dashed lines indicate the bore amplitude estimated from theory as described by Haghi et al. (2017). Modified from Haghi et al. (2017) and modeled after Rottman and Simpson (1989).

8 with speeds in excess of $15 \mathrm{~m} \mathrm{~s}^{-1}$. The depths of the stable layers are also quite different. The stable layer in the simulation reached depths of $\sim 1.5 \mathrm{~km}$ [see Fig. 6 in Parker (2008)], while the composite shows increased stability below the NLLJ at $\sim 500-600 \mathrm{~m}$, as evidenced by a layer of high CIN (Fig. 3). Differences also exist in the environmental wind profiles. The Parker (2008) simulations had linear shear below $3 \mathrm{~km}$, while the winds in Fig. 3 reveal a southerly jet at a height of just above $500 \mathrm{~m}$, topped by a peak in the westerly winds near $\sim 1 \mathrm{~km}$ in height. The French and Parker (2010) simulations did contain a jet profile, but the jet was centered at $1.5 \mathrm{~km}$ in height, with constant winds below $\sim 750 \mathrm{~m}$.

While Parker (2008) and French and Parker (2010) did not apply hydraulic theory to characterize flow regimes, we can use the available description of the "DEEP-unlim" simulations by Parker (2008) to roughly estimate the likely range of values for $\mathrm{Fr}$ and $H$. From Fig. 7 in their study, we estimate $C_{\mathrm{dc}}$ from the theoretical cold pool speed to be $\sim 20-30 \mathrm{~m} \mathrm{~s}^{-1}$ and $U_{\text {inv }}$ at $\sim 10 \mathrm{~m} \mathrm{~s}^{-1}$, noting the vertical shear in the lowest levels is given as $\sim 18 \mathrm{~m} \mathrm{~s}^{-1}$. The stable layer depth $h_{o}$ is estimated to be $\sim 1.5 \mathrm{~km}$, and the cold pool depth $d_{o}$, as taken from their Fig. 6 , is estimated to be $\sim 2 \mathrm{~km}$. A value of $300 \mathrm{~K}$ was estimated for $\theta_{\mathrm{vw} \_ \text {inv }}$. The change in potential temperature across the inversion varies with time so that values of both 3 and $10 \mathrm{~K}$ were used to estimate $\Delta \theta$, with the larger value describing conditions later as the cooling progresses.

These admittedly rough estimates translate to an $H$ of $\sim 1.3$. The values of Fr range from $\sim 3.3$ during the early stages of nocturnal evolution to $\sim 1.3$ at later times when the cold pool speed is reduced and the inversion is stronger. The initial values for $H$ and $\mathrm{Fr}$ fall within the supercritical regime. The balance subsequently evolves toward the border between the supercritical and partially blocked regimes where type $\mathrm{C}$ bores are generated and finally moves into the partially blocked flow regime (Fig. 5). Thus, the simulations start well outside the regimes typically observed in the IHOP_2002 data (Fig. 5), but tend to approach the observed values later in the simulations (Fig. 5). In the simulations, the transition of the convective system from driven by a rapidly moving cold pool to an elevated system with a bore occurs after $\sim 6-8 \mathrm{~h}$. According to Parker (2008), the cold pool in the simulation might include a transition to a type $\mathrm{C}$ bore before that time.

In contrast, the results of Haghi et al. (2017), as discussed earlier (Fig. 5), indicate that a partially blocked flow regime with the generation of a bore is the most likely outcome of the interaction between the environment and the cold pool as early as 2100 LST, with the tendency for bores to be generated increasing as the night progresses (Fig. 5). This finding of Haghi et al. is 
also supported by their observation that shows cold pools frequently trigger a bore that moves away from the density current. Thus, the observed convective systems can have both a bore and a cold pool. The analysis of the surface observations in the Haghi et al. (2017) study provides evidence that the bores in their study were generally not type $\mathrm{C}$ bores. Contrasting the observations with the simulations, it is evident that the squall lines in the simulations are likely to remain in the stalled phase for far longer than in the observations. The stalled phase in the simulations is characterized by a weakening cold pool producing strong ascent that lifts boundary layer air into the convective system.

In addition to the previously mentioned differences in cold pool speeds between the observations and the simulation, the bore speeds show similar differences. The bores that are generated in the Parker (2008) and French and Parker (2010) simulations move at a speed between $\sim 20$ and $30 \mathrm{~m} \mathrm{~s}^{-1}$. In the observations that were utilized in the Haghi et al. study, we were only able to obtain velocities for 59 of the 65 observed bore-like disturbances. Of the 59 events, the median velocity was $\sim 11 \mathrm{~m} \mathrm{~s}^{-1}$, with only five bores having speeds in excess of $20 \mathrm{~m} \mathrm{~s}^{-1}$. The tendency toward more rapid speeds of the bores in the simulation is likely due to relatively deeper stable layers.

The convective instability within the composite and the simulations is also quite different. In the simulations, the cold pool continued to lift air to its level of free convection during a prolonged stalled phase until the CAPE vanished in the boundary layer, and the system was maintained by bore lifting of a layer of high-CAPE air centered between 1.5 and $2 \mathrm{~km}$ in height [see Fig. 5 of Parker (2008)]. In contrast, the observed nocturnal CAPE profiles in the lowest $1.5 \mathrm{~km}$ are more favorable for convection throughout the night (Fig. 3). For example, positive CAPE remains in the boundary layer throughout the night, and while the CIN is quite large near the surface (in excess of $350 \mathrm{~J} \mathrm{~kg}^{-1}$ ), the magnitude decreases rather rapidly with height. Understanding the differences between the convective systems in the simulations and those that result from the interaction between the observed stability fields and bores and cold pools would benefit from more realistic idealized simulations. Still, from this comparison, it is clear that the simulations describe one possible mode of the evolution of organized nocturnal convective systems, but not the full breadth of system evolution, such as observed during IHOP_2002. We do caution the reader on applying the results of Haghi et al. (2017) to all nocturnal convective systems observed in IHOP_2002, since some convective systems did not generate radar fine lines and thus were not investigated in the Haghi et al. study.

\section{Characteristics of the observed wave disturbances}

\section{a. Lifting observed by MAPR}

The role of waves in initiating or maintaining convection depends on both the convective instability and the magnitude of the wave-induced ascent. In this section, we document the ascent and the vertical structure of the waves through measurements made at the Homestead site. Information on the vertical displacement of scattering layers for 13 wave events on seven nights is given in Table 1 . Two additional disturbances were not included in Table 1 , since the events took place when MAPR data were unavailable. Several of these events have been discussed in the literature as case studies (e.g., Knupp 2006; Koch et al. 2008a,b; Tanamachi et al. 2008; Marsham et al. 2011), which concluded the waves were bore disturbances, and Haghi et al. (2017) concluded that these events were bore disturbances generated at the leading edge of the convective outflows. In interpreting Table 1, the relatively shallow height coverage of MAPR (at either 4 or $5 \mathrm{~km}$, depending on the settings) meant that displacement heights could sometimes not be obtained for layers lifted from heights of $\sim 2.5-3 \mathrm{~km}$ or higher, since the bore ascent lifted these scattering layers above the top of the MAPR domain. Thus, the reader is cautioned that the results systematically underestimate vertical displacement for scattering heights initially above $\sim 2.5-3 \mathrm{~km}$.

Given this caveat, the average maximum and net displacements of these 13 events (Table 1) were 892 and $658 \mathrm{~m}$, respectively. The largest maximum displacements were $\sim 1700 \mathrm{~m}$, while the largest net displacement was $\sim 1400 \mathrm{~m}$. Our estimates of vertical displacements seem reasonable based on past case studies of bores during IHOP_2002, as, for example, Knupp's (2006) case study documented a maximum vertical displacement of $\sim 2 \mathrm{~km}$ and net displacements of 600-900 m. Our maximum upward displacements and the net upward displacements of the scattering layers are also summarized in Figs. $6 \mathrm{a}$ and $6 \mathrm{~b}$, respectively. These displacements show a great deal of scatter, particularly for scattering layers originating above $\sim 800 \mathrm{~m}-1 \mathrm{~km}$. Another characteristic evident in Table 1 and Fig. 6 is that significant lifting, and sometimes even the largest upward displacements, occur for layers originating well above the nocturnal stable layer. Thus, these waves in this nocturnal environment should be treated as a lowertropospheric phenomenon, rather than simply as "waves on an inversion" or stable boundary layer disturbances in the lowest $\sim 500 \mathrm{~m}$. This distinction is important since 


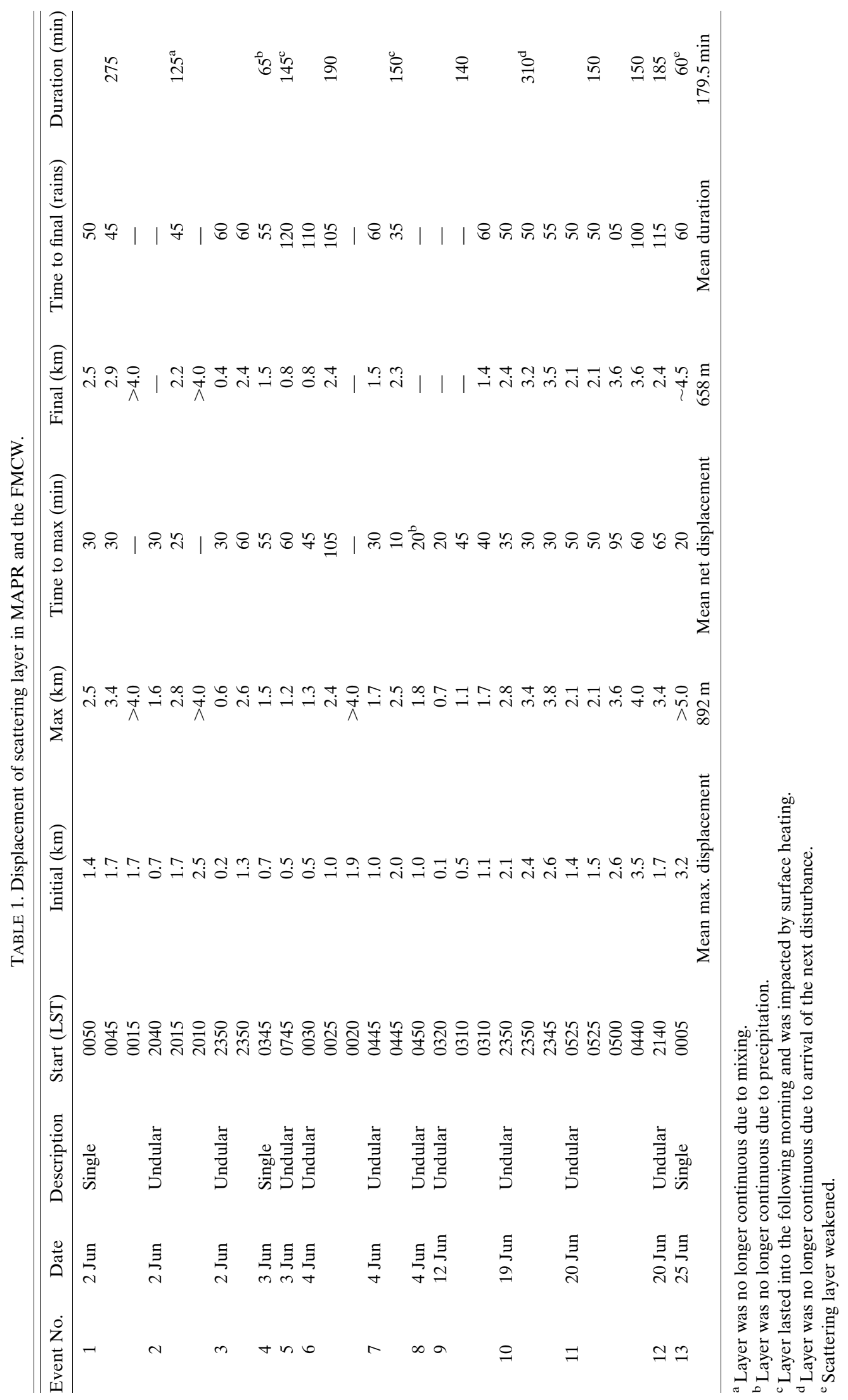



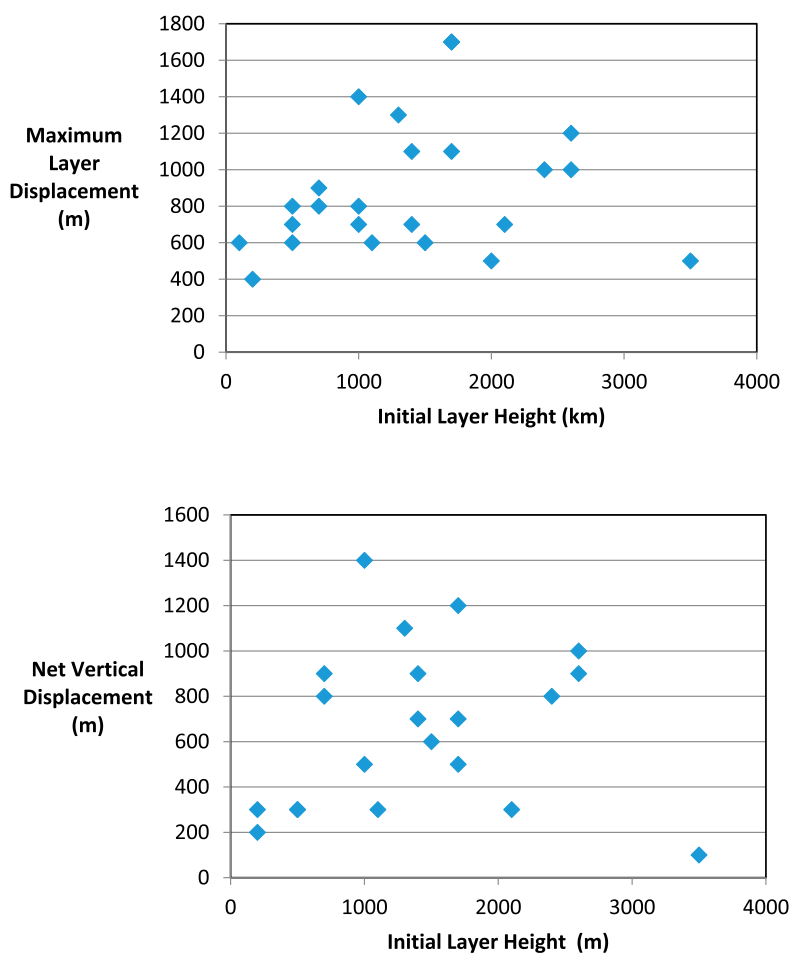

FIG. 6. The initial height of scattering layers vs the vertical displacement of these layers as detected by MAPR and the FM-CW at the IHOP_2002 Homestead site as a function of time. (a) Maximum vertical displacement following the passage of the bore. (b) Net vertical displacement following the passage of the bore.

the lifting clearly extends into convectively favorable vertical layers near and above the NLLJ (Fig. 3).

Table 1 also includes the time from the arrival of the leading edge of the disturbance until the maximum upward displacement was observed, with estimates ranging from 10 to $105 \mathrm{~min}$. Given a range of observed speeds of $8-15 \mathrm{~m} \mathrm{~s}^{-1}$, the maximum upward displacement occurs on the order of $\sim 5-100 \mathrm{~km}$ behind the leading edge of the bore, with the longer times being associated with undular bores and the more rapid ascent with lifting from a single bore. Since the location of the maximum upward displacement is quite relevant for convective initiation, this result shows the difficulty in attributing convective initiation to bore ascent, as layers will typically reach their maximum displacement many tens of kilometers behind the leading edge of the bore. Following this lifting, the displaced layers remained relatively constant with time, as, for example, shown earlier in Fig. 2. The MAPR measurements also allow us to estimate the time from the initial upward displacement until the displaced layer starts to slowly descend back to its original height. These estimates of longevity (Table 1) indicate that more than $5 \mathrm{~h}$ can elapse before the upward-displaced layers begin the slow descent back their original height. In many cases, a variety of physical processes (e.g., the arrival of a cold pool, sunrise followed by the growth of the boundary layer from solar heating, the occurrence of another disturbance, convection, the dissipation of the scattering layer) occurred before the beginning of the observed descent. The persistence of these lifted layers suggests a substantial region of lifted air occurs behind the leading edge of the bore. For example, assuming a reasonable range of bore speeds of $\sim 8-15 \mathrm{~m} \mathrm{~s}^{-1}$ based on Haghi et al.'s (2017) observations and an upper bound for the persistence of $\sim 5 \mathrm{~h}$, a bore would propagate $\sim 140-270 \mathrm{~km}$ before the upward-displaced layers would even begin to start to descend back to their initial heights. Given that these disturbances can extend for lengths of hundreds of kilometers, as indicated by the radar fine lines, these results suggest that large areas of upward-displaced air (of order $10000 \mathrm{~km}^{2}$ or greater) can occur behind the leading edge of these disturbances. This regional destabilization of the environment is similar to the proposed gregarious nature of tropical convection by Mapes (1993), although our result is from a bore generated in partially blocked flow.

\section{b. Example of variations in wave structure}

While nearly all the events investigated showed a clear maximum in the vertical motions at heights near or below $1.5 \mathrm{~km}$, the results in Table 1 show a great deal of variation in the vertical structure. We will illustrate this variation through using MAPR data for cases that had greater complexity than a simple bore structure and had strong lifting above the $1-1.5-\mathrm{km}$ level. For example, in the 2 June event, shown earlier in Fig. 2, a single upward displacement of the scattering layer is observed as the layer is lifted from $\sim 2$ to $4 \mathrm{~km}$. Thus, strong ascent occurs well above the heights expected for strong bore ascent. This lifting could be due to a low-frequency gravity wave $n=2$ mode associated with buoyant convection, given that the feature suggests evidence of ascent in the lower troposphere. Unfortunately, the MAPR measurements do not extend into the upper troposphere, where descent with this mode would occur.

The second case selected to illustrate variations in wave structure was the 3 June event ( 2 in Table 1 ), which contained a rather complicated wave structure, with the three different pulses of upward displacement of the scattering layer (Fig. 7). The strongest vertical motion was found between $\sim 1$ and $1.5 \mathrm{~km}$, consistent with the expectation for a bore in the NLLJ environment (e.g., Haghi et al. 2017). The displacements of the scattering layers, however, were more complex. The first upward displacement at the Homestead site occurred aloft in the layer between $\sim 2.5$ and $4 \mathrm{~km}$, followed by the subsequent lifting of a layer initially at $\sim 1.7 \mathrm{~km}$ in height, 

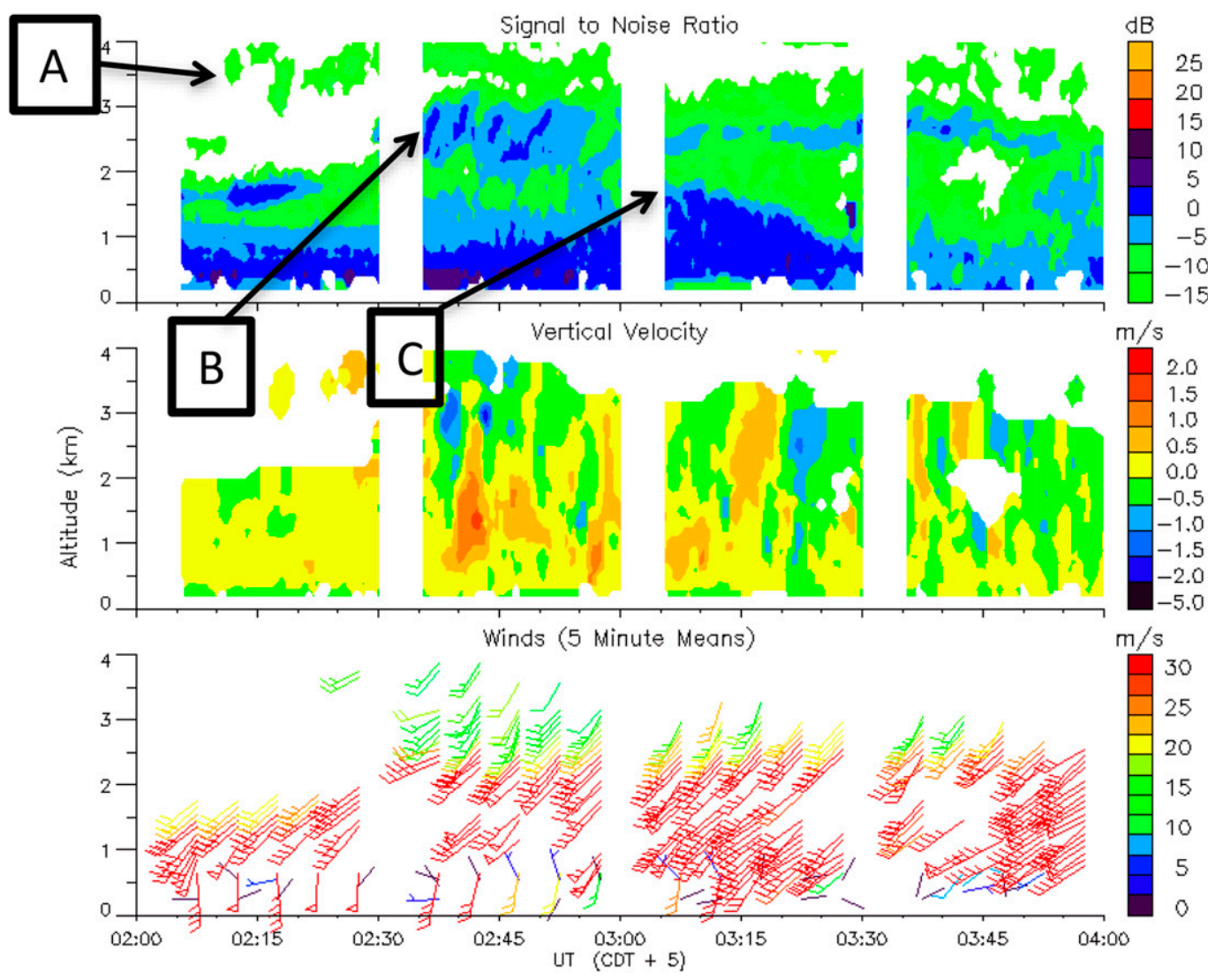

FIG. 7. As in Fig. 2, but for 3 Jun 2002. Note the depiction of three areas of lifting (labeled A, B, and C) in the MAPR data with the scattering layers at lower levels arriving at progressively later times. Note some ground clutter is suggested by the light winds in the vertical layer containing the LLJ. In addition, the absence of horizontal winds in the lower levels is due in large part to data rejected because of the presence of clutter.

and a subsequent third pulse of ascent associated with the lifting of the stable boundary layer. These three disturbances were generated by a mesoscale convective system to the west of the Homestead site with a northnortheast-south-southwest orientation (Fig. 8). Since the initial upward displacement aloft did not correspond to a fine line in the radar data (Fig. 8a), one possibility is that the first lifted layer is a response to low-frequency gravity waves generated by buoyant convection and extending through the troposphere (e.g., Nicholls et al. 1991; Mapes 1993; Fovell 2002). A similar disturbance was noted in Knupp's (2006) study of the 21 June event (event 12 in Table 1), but the disturbance was not attributed to a low-frequency gravity wave. The second upward displacement in this event (Fig. 7) was associated with a distinct radar fine line ${ }^{2}$ that originated from

\footnotetext{
${ }^{2}$ Given the low reflectivity values of clear-air returns associated with fine lines, bores are only detected within the clear-air coverage of the radar.
}

and propagated away from this convective system (Fig. 8b). The initial ascent aloft took place $\sim 57 \mathrm{~min}$ before the third upward displacement, again illustrating the difficulty in attributing convective initiation through tracking the radar fine lines associated with bores, as these first two pulses of lifting could initiate convection well ahead of the stable layer disturbance. This second net upward displacement was also associated with smaller-scale disturbances in the signal to noise and the vertical motions on the lifted layer between 2035 and 2050 LST (Fig. 7). The presence of strong vertical shear associated with these disturbances (Fig. 7) raises the possibility of shearing instability on the lifted layer. These smaller-scale disturbances on lifted layers were found in other cases, such as between 0100 and 0125 LST 2 June (Fig. 2).

The 4 June event ( 8 in Table 1 ) the following day illustrates another example of the variations in wave structure (Fig. 9). In this event, the increase with time and height in the vertical distance among three different scattering layers suggests that over the event's lifetime, 

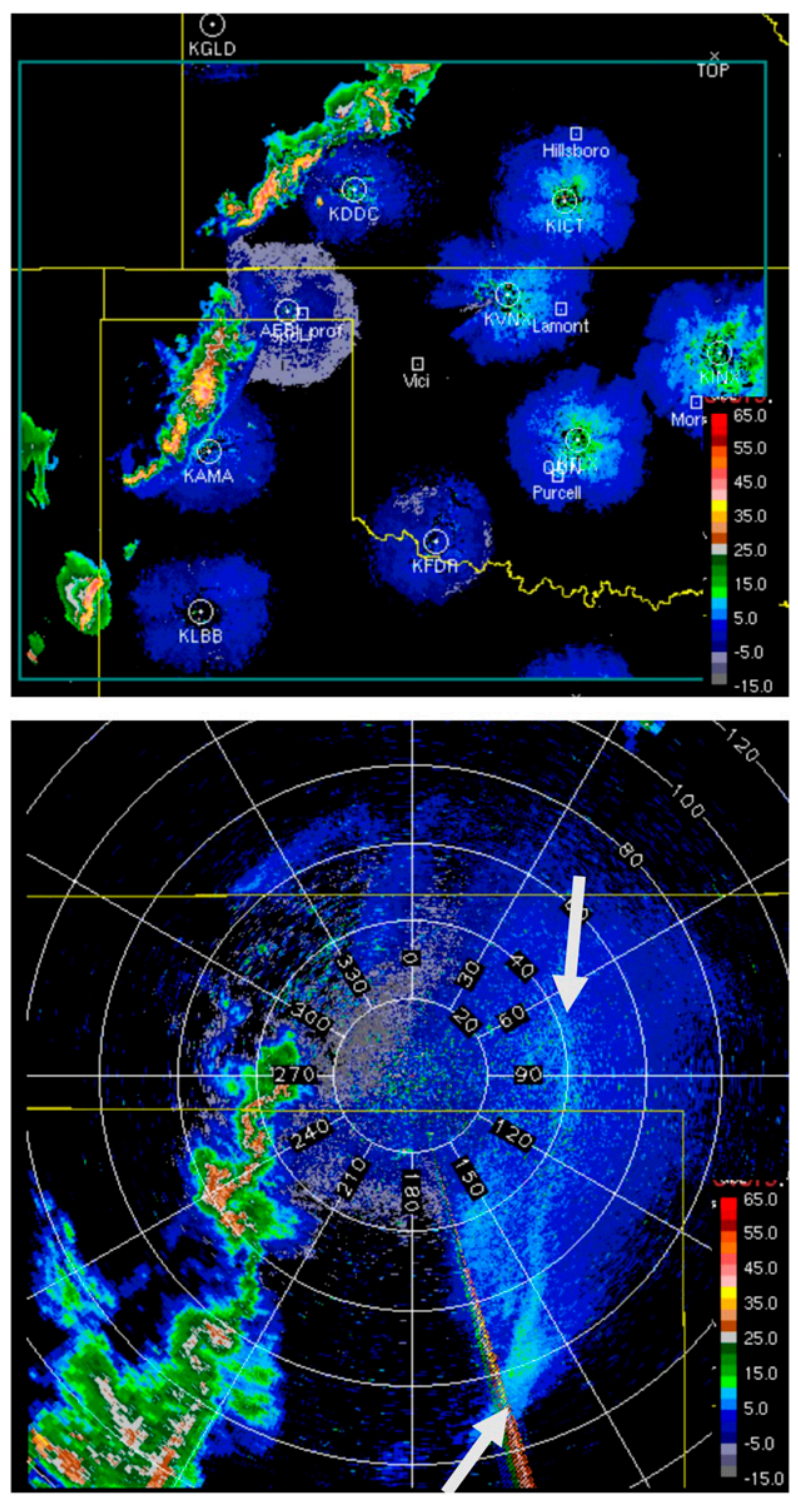

FIG. 8. (a) Composite of radar reflectivity from the S-Pol and the operational network at 2015 LST 3 Jun 2002. The color scale for the radar reflectivity is shown in the lower-right-hand corner of the diagram. The locations of the operational radars and the ARM sounding sites are shown along with the location of the Homestead remote sensing site in the Oklahoma Panhandle. (b) Radar reflectivity from the S-Pol taken from a low-level surveillance scan during IHOP_2002 at 2130 LST 3 Jun 2002. The azimuth angles and radar range $(\mathrm{km})$ are indicated with the color scale depicted in the lower-right-hand corner of the diagram. The radar fine line associated wave is identified by the white arrows.

the wave amplitude appears to increase with height. This case is described in detail through observational analysis and high-resolution numerical modeling by Koch et al. (2008b). Their study termed the wave structure aloft as an "indirect influence" of the bore resulting in gravity wave motions aloft. Haghi et al. (2017) found that multiple wave ducts may exist above the stable boundary layer, allowing separate wave disturbances to propagate at different velocities in distinct ducts existing at different heights. The large upward displacements of layers located well above the stable boundary layer on 3 and 4 June and other cases in Table 1 imply that this indirect influence or low-frequency gravity waves are likely a common occurrence in this dataset. Parker (2008) proposed that vertical shear above the stable boundary layer is important in maintaining lift via the Rotunno et al. (1988) mechanism. The presence of deeper ascent with the bore's lifting stable air creating negative buoyancy aloft suggests that deeper shear would be beneficial for nocturnal convection.

\section{c. Observed lifting within the context of wave ducts and trapping of wave energy}

The presence of strong lifting throughout the lower troposphere in association with variable wave structures aloft would not be expected in this variant of hydraulic theory, since the two-layer model has a stable layer containing the bore topped by an infinitely deep neutral layer. In this framework, the maximum updraft has been proposed to occur at the top of the stable layer, with the updraft exponentially decaying above this height. In our composite (Fig. 3), the layer above the nocturnal boundary layer is slightly stable, as indicated by small values of CIN extending up to $\sim 2.5 \mathrm{~km}$ (above that height, the CAPE is negligible so that the CIN is not calculated). This observed profile would allow wave responses above the stable nocturnal boundary layer. The stability aloft can also impact the evolution and longevity of the bore, since the vertical motions above a lower-level stable layer containing the bores can weaken the amplitude of the bore in the lowest layers (Crook 1986). The presence of vertical shear in the observations can also amplify the response. These wave responses above the stable boundary layer are of practical interest, given these layers aloft contain significant CAPE and reduced CIN.

To place the mean conditions in the context of wave trapping, we follow Haghi et al.'s (2017) application of linear wave theory. ${ }^{3}$ As in Haghi et al. and the relevant references therein, the linearized governing equations lead to the Taylor-Goldstein equation:

$\bar{w}^{\prime \prime}-m^{2}(z) \bar{w}=0$

$m^{2}=l^{2}-k^{2}=\frac{N^{2}}{\left(U-C_{b}\right)^{2}}-\frac{\partial^{2} U / \partial z^{2}}{\left(U-C_{b}\right)}-k^{2}$,

\footnotetext{
${ }^{3}$ The reader is referred to Haghi et al. (2017) for further information on the assumptions utilized in this derivation.
} 


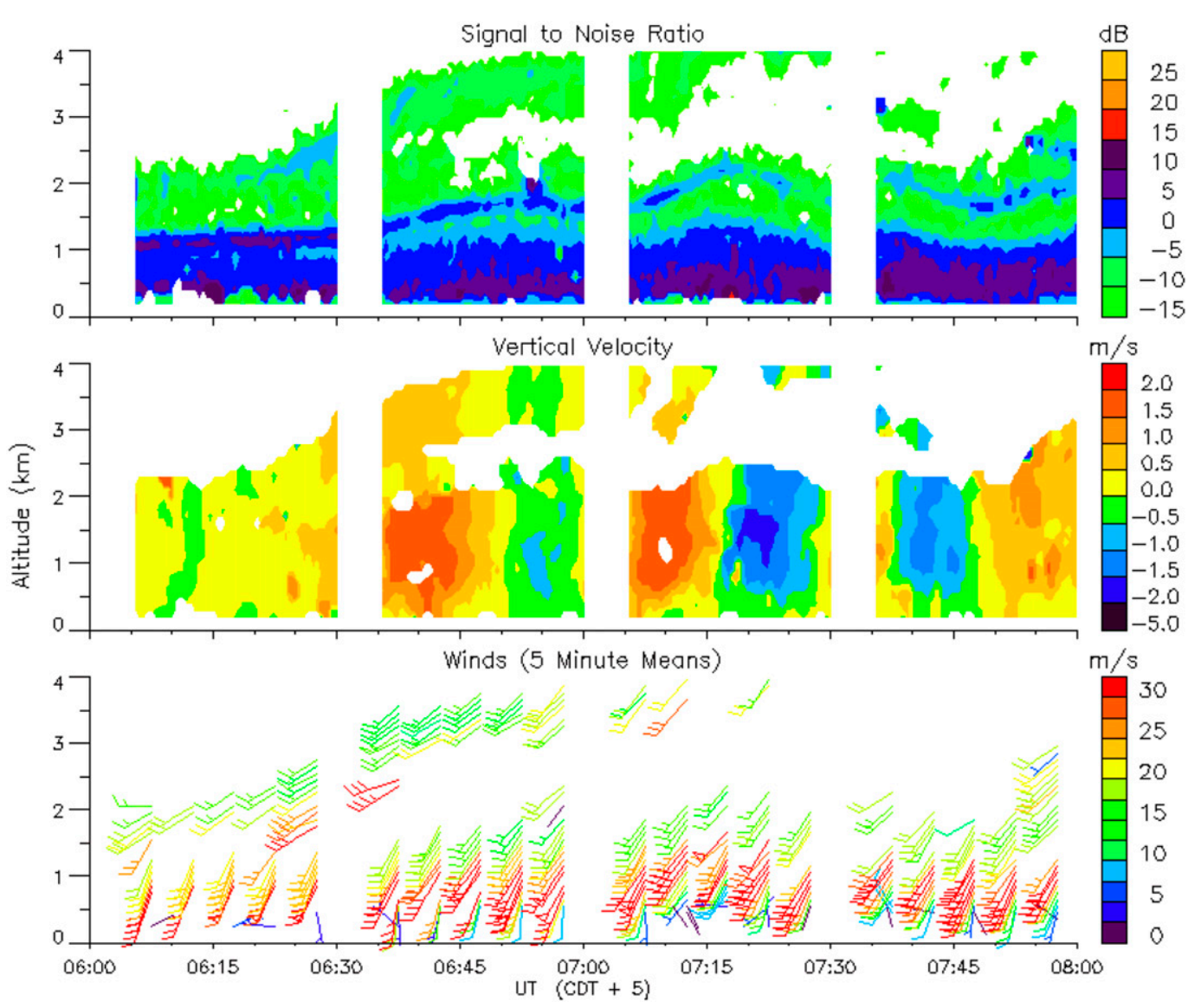

FIG. 9. As in Fig. 2, but for 4 Jun 2002. The increasing vertical distance between the scattering layers with time suggests an increase in the wave amplitude with height may have been present during the event's lifetime. Note the presence of some lighter winds within the layer containing the LLJ is likely due to the presence of ground clutter.

where $\bar{w}$ is the vertical velocity, $m$ is the vertical wavenumber, $l^{2}$ is the Scorer parameter (Scorer 1949), $k$ is the horizontal wavenumber, $C_{b}$ is the ground-relative speed of the bore, $U(z)$ is the horizontal wind, and $N$ is the Brunt-Väisälä frequency, given by

$$
N=\sqrt{\frac{g}{\theta_{v}} \frac{\partial \theta_{v}}{\partial z}},
$$

with $\theta_{v}$ is the virtual potential temperature. ${ }^{4}$ The first term in (4) is often referred to as the "stability term" due to the dependence on the Brunt-Väisälä frequency. The second term is often termed the "curvature term," since the second derivative of the horizontal wind pertains to the curvature of the vertical profile of the horizontal wind.

The vertical profile $m^{2}$ is utilized to identify favorable wave ducts (Knupp 2006; Koch et al. 2008a), with

\footnotetext{
${ }^{4}$ We use $\theta_{v}$ instead of $\theta$, following Koch et al. (1991).
}

trapping in a layer characterized by $m^{2}<0$ located above the wave duct with $m^{2}>0$. The upper layer supports only exponentially decaying "evanescent" motions (Baines 1995). Haghi et al. (2017) found that the trapping of wave energy in this dataset was generally associated with the curvature term, as had been suggested in several case studies. The composite wind profiles (Fig. 10) add further support to the role of the curvature term. The curvature term, however, varies with orientation due to the presence of jet-like profiles in both the $u$ and $v$ components. Haghi et al. (2017) and Blake et al. (2017) also noted this 3D variation in wave trapping. In our composite, wave trapping from the curvature term in (4) appears to be more pronounced for the southerly component of the NLLJ (Fig. 10). Thus, bores on the southern edge of convective outflows are likely to typically maintain their amplitude and be longlived. Along the eastern edge of a convective outflow, deeper lifting from vertically propagating disturbances may occur instead of long-lived bores that move ahead of the cold pool. 

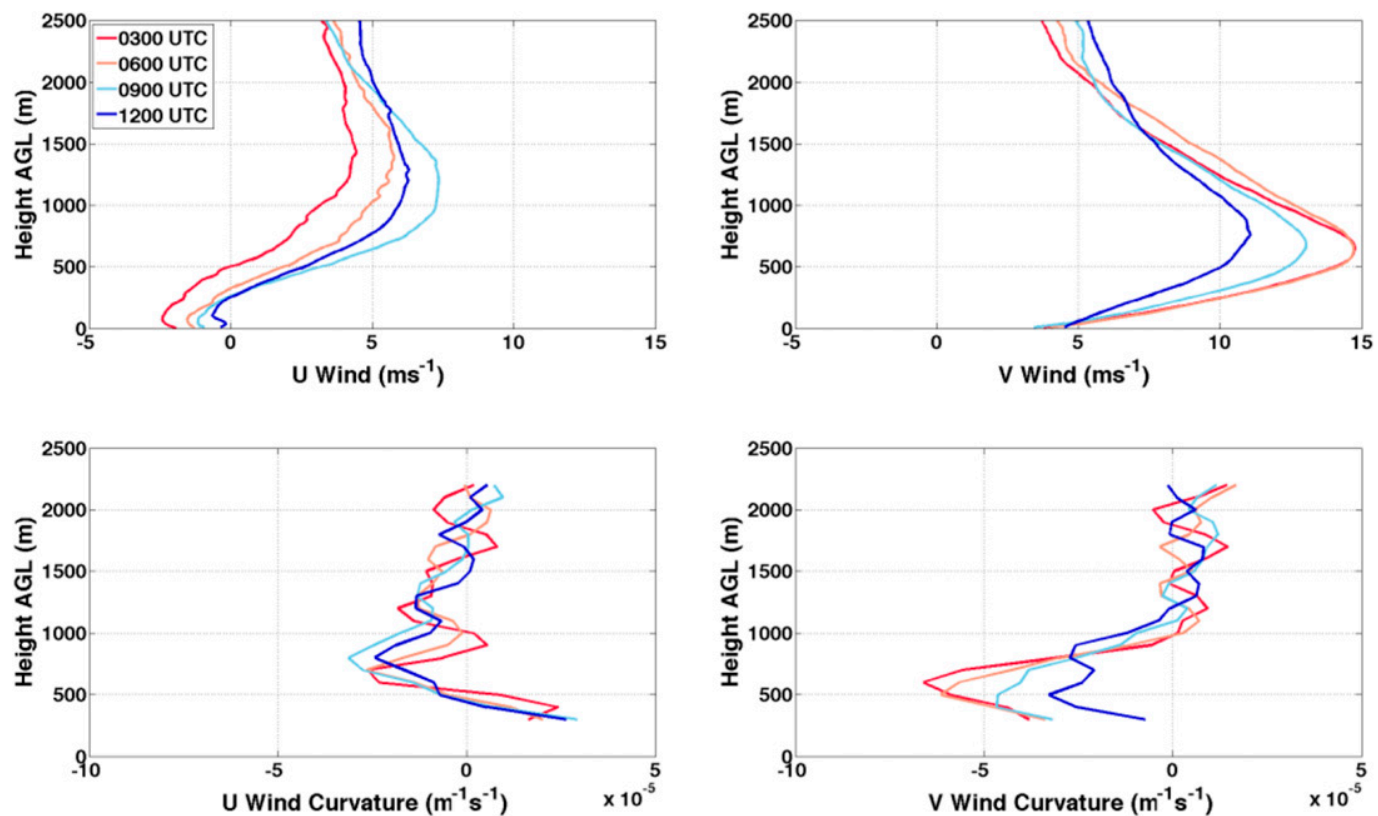

FIG. 10. Vertical profiles of the (left) $u$ and (right) $v$ components of the wind along with the second derivative of these profiles with respect to height in order to represent the curvature term in (4).

This classic linear theory does not explain the existence of the waves well above the trapping layer, given the assumption of a stable layer trapped by a deep layer of neutral stability. Two possibilities may explain these waves. The first explanation, which was stated earlier, is that these waves aloft could be due to the "indirect influence" of the bore on the stable atmosphere above the trapping layer. The 4 June event in Fig. 9 is perhaps an example of this behavior, as the vertical motions are at a maximum in the lowest $1.5 \mathrm{~km}$, but the lifting aloft remains in phase with the lower-level disturbance. The events shown in Figs. 2 and 7, however, suggest waves aloft that are not in phase with lower-level bore ascent. These waves aloft may be low-frequency gravity waves
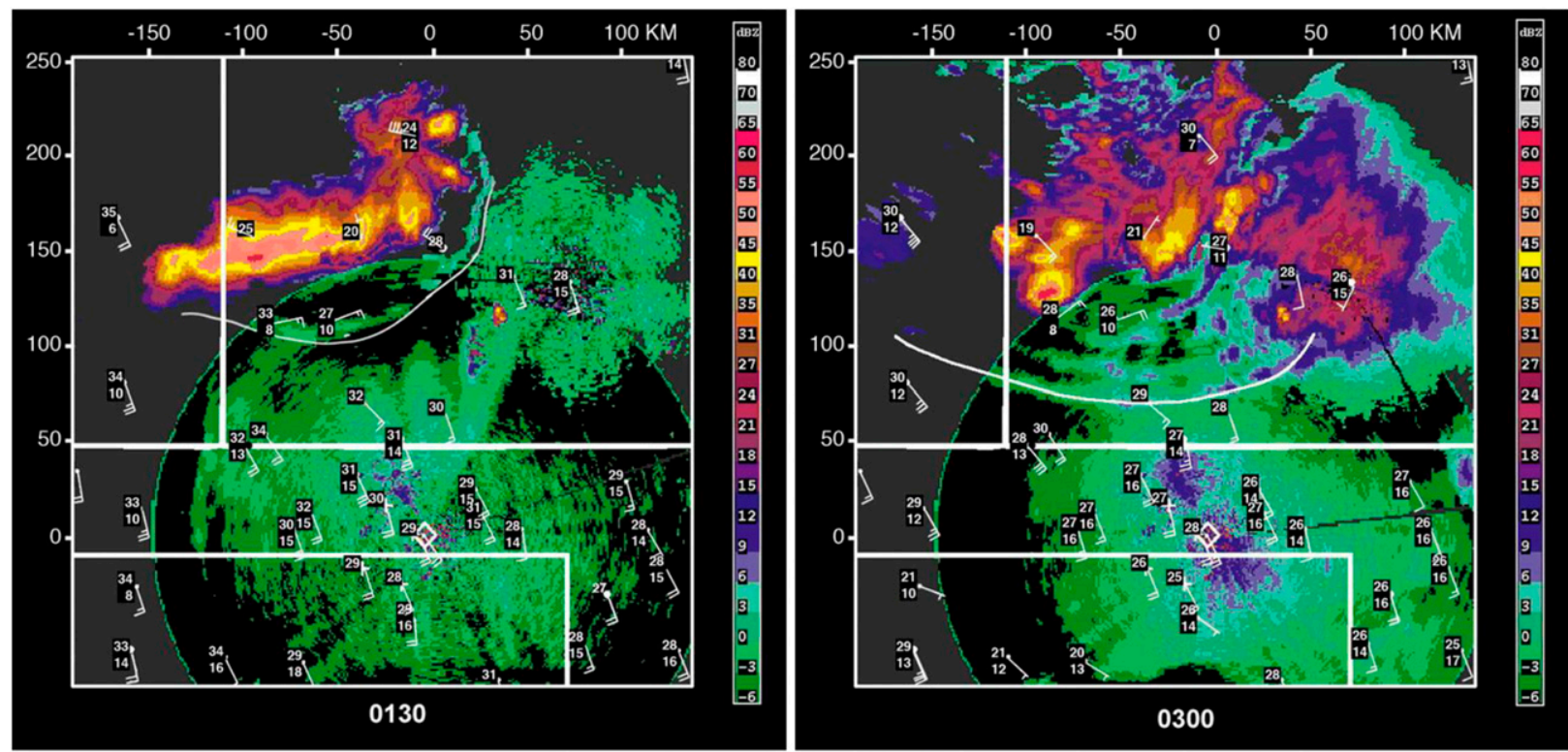

FIG. 11. Surface data and radar reflectivity at (a) 1930 and (b) 2130 LST 20 Jun 2012. The white line indicates the leading edge of the gust front at 1930 LST that has transitioned into an undular bore at 2100 LST. Taken from Koch et al. (2008b). 
a)

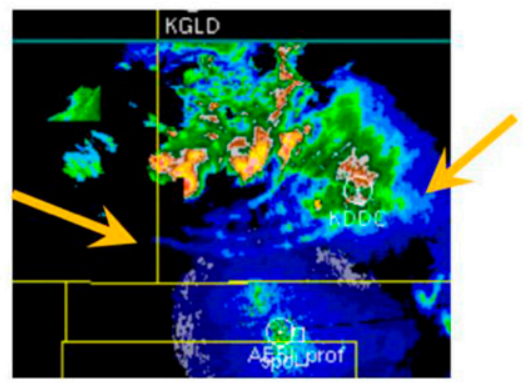

b)

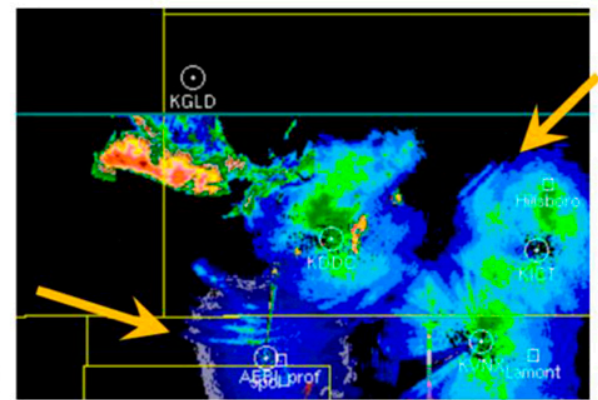

c)

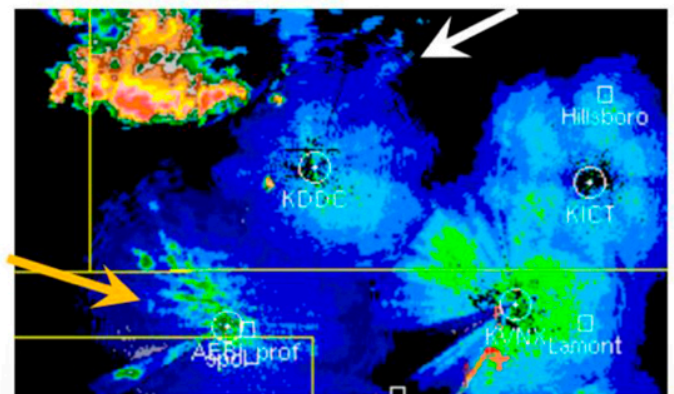

d)

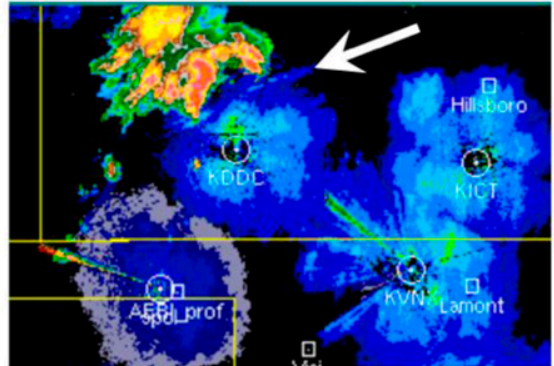

e)

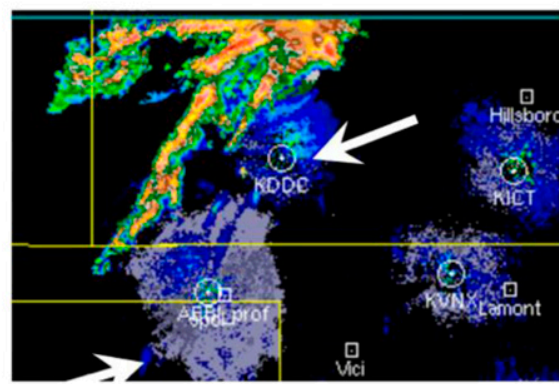

f)

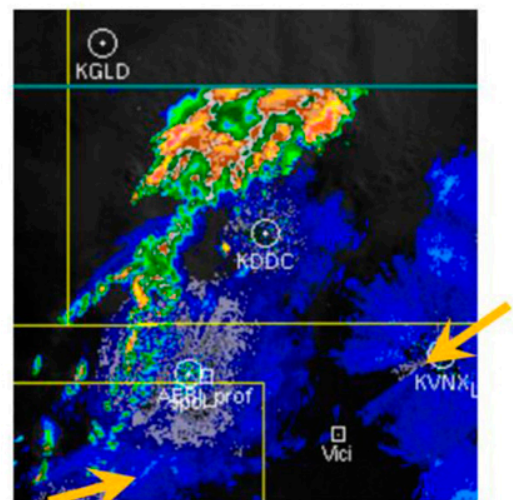

FIG. 12. Radar composite constructed from the operational radar network and the NCAR S-Pol from IHOP_2002 on 20 Jun 2002 at 2-h intervals: (a) 2100, (b) 2300, (c) 0100, (d) 0300, (e) 0500, and (f) 0700 LST. The arrows denote the location of radar fine lines that primarily had the appearance of bores. The differences in the color of the arrows are designed to help illustrate the sequential formation and propagation of the various fine lines.

that would be long-lived or waves ducted in layers aloft, as noted by Haghi et al. (2017).

\section{Waves and convection}

We will next explore the impacts of wave lifting on convective instability and the possible initiation and maintenance of convection, beginning with observations on the night of 19 June and the early morning hours of 20 June. Koch et al. (2008a) present an excellent and detailed analysis of the structure and evolution of three undular bores initiated by convective outflows on this night. The initiation and subsequent early evolution of one of these bores begins with a convective outflow that moves to the south ahead of a squall line at 1930 LST (Fig. 11a). The radar reflectivity just $90 \mathrm{~min}$ later at
2100 LST (Fig. 11b) reveals that convection continues behind the bore, but becomes more cellular as an undular bore forms and propagates away from the convection. As the undular bore expands toward the east and south, organized convection continues for another $10 \mathrm{~h}$ in the wake of the leading edge of the bore (Fig. 12). During this time (Fig. 12), the bore approached $500 \mathrm{~km}$ in length and moved over a distance of $\sim 100 \mathrm{~km}$. These estimates meant that the bore propagated over an area of $\sim 5 \times 10^{4} \mathrm{~km}^{2}$. While the first bore moved out of the IHOP_2002 radar composite and became increasingly difficult to track, additional disturbances were generated in association with convective outflows (Figs. 12c-e). A closer examination of these fine lines utilizing the S-Pol data at 0530 and 0700 LST (Fig. 13) suggests convection 

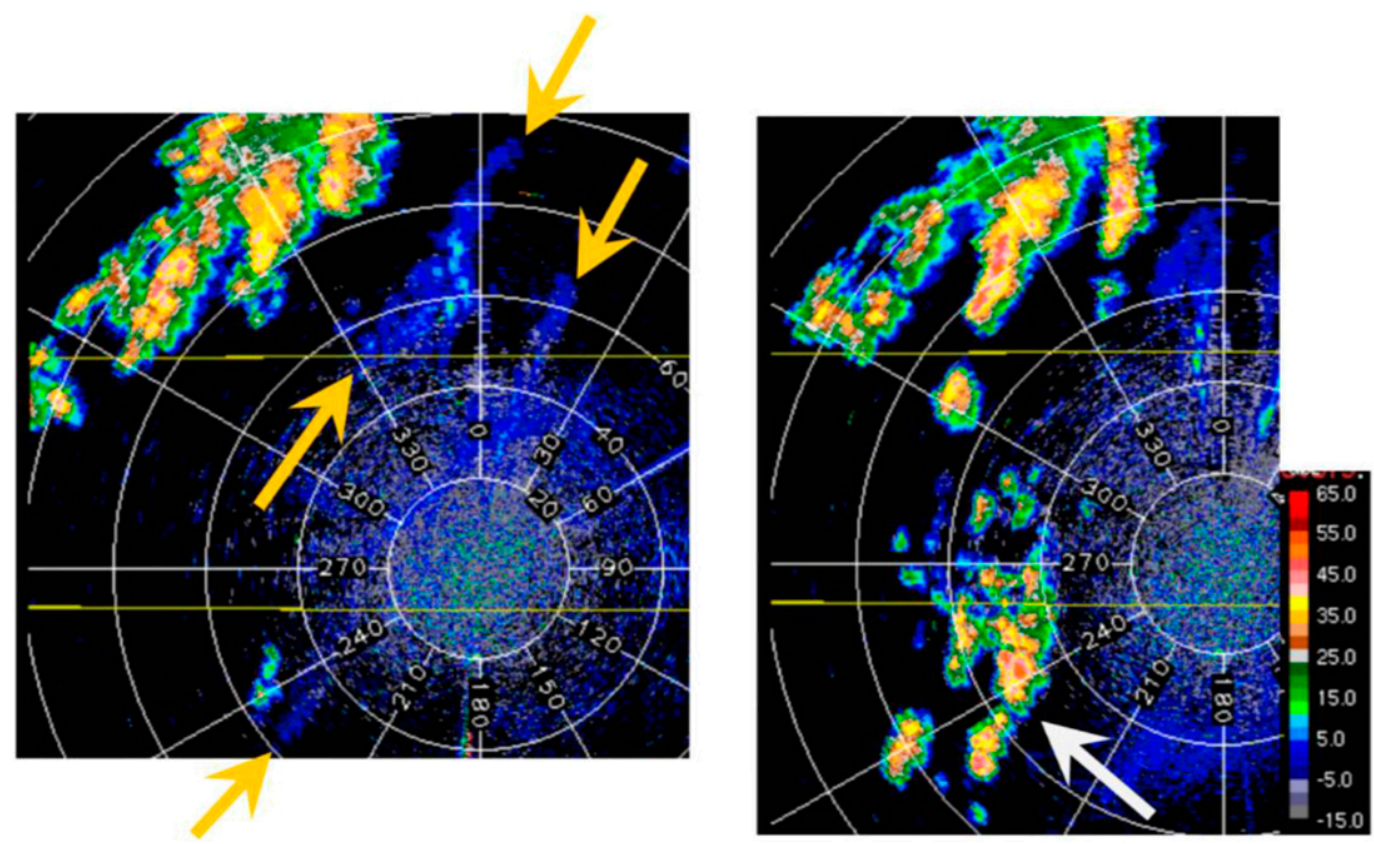

FIG. 13. Radar reflectivity from the S-Pol taken from a low-level surveillance scan during IHOP_2002 on 20 Jun 2002. The azimuth angles and radar range $(\mathrm{km})$ are indicated with the color scale as shown in Fig. 9b. Reflectivity at (a) 0530 LST showing fine lines that originated from the convection as indicated by the arrow and (b) 0600 LST showing the initiation of new convective cells (white arrows). Periods of enhanced vertical motion were also observed at MARP ahead of this system (not shown).

was initiated near or behind the leading edge of these additional bores.

Since convection continued in the wake of the leading edge of the bore, we will investigate the stability in the wake of these bores utilizing soundings taken at the Homestead site. The vertical profiles of CAPE and CIN (Fig. 14) are shown for a sounding launched just after the arrival of the first bore and a sounding from the previous and following afternoons. The two daytime profiles have high CAPE and low, but significant, CIN in the boundary layer, consistent with the mean conditions in the composite (Fig. 3). The postbore nocturnal profile (Fig. 14) is characterized by favorable conditions for elevated but deep convection, with CIN less than $50 \mathrm{~J} \mathrm{~kg}^{-1}$ between $\sim 2$ and $2.8 \mathrm{~km}$ and a deep layer of high CAPE between 1.5 and $3 \mathrm{~km}$, with a maximum CAPE of $\sim 1400 \mathrm{~J} \mathrm{~kg}^{-1}$ at $2 \mathrm{~km}$. In contrast to the mean conditions, the nighttime soundings after the arrival of the bore have far less CIN than the daytime soundings so that the nocturnal conditions require less forcing to initiate than conditions during the day (Fig. 14).

The second case investigated took place on 4 June. The following analysis builds upon the Koch et al. (2008b) study that also investigated the 4 June bore. In this case, convection occurred in the wake of the observed bore fine lines, as depicted in the IHOP_2002 radar composite at 0130 LST 4 June (Fig. 15). The sequence of radar reflectivity (Figs. 16a,b) shows that $2.5 \mathrm{~h}$ later, at $0400 \mathrm{LST}$, convection was triggered at the leading edge of a second bore. This convection moved to the north, away from the leading edge of the second bore, as the bore continued to move relatively rapidly toward the southeast. Convection continued in the wake of the bores until sunrise (Fig. 16c).

Koch et al. (2008b) described the impact of the passage of bores as creating more favorable CAPE and CIN, arguing that the decrease of surface-based CIN from lifting aloft was likely to be more important than the more modest increases in CAPE. The potential role of this bore in creating a more favorable sounding for convection can be examined through applying ascent based on theory to soundings launched ahead of the bore. We first estimate the bore amplitude from theory (see Fig. 5; Haghi et al. 2017) and assume that the displacement varies linearly from the surface to the top of the layer of strong stability, with the maximum lift realized at the top of the inversion. The application of this method does not take into account repeated lifting by undular disturbances or the passage of multiple bores, nor does it account for differences between the actual vertical profile of ascent and the predictions by theory. To include the frequently observed lifting above the stable nocturnal boundary layer, the ascent linearly decreased from a maximum at the inversion to zero at a height of $3 \mathrm{~km}$. This approach was applied to two ARM 

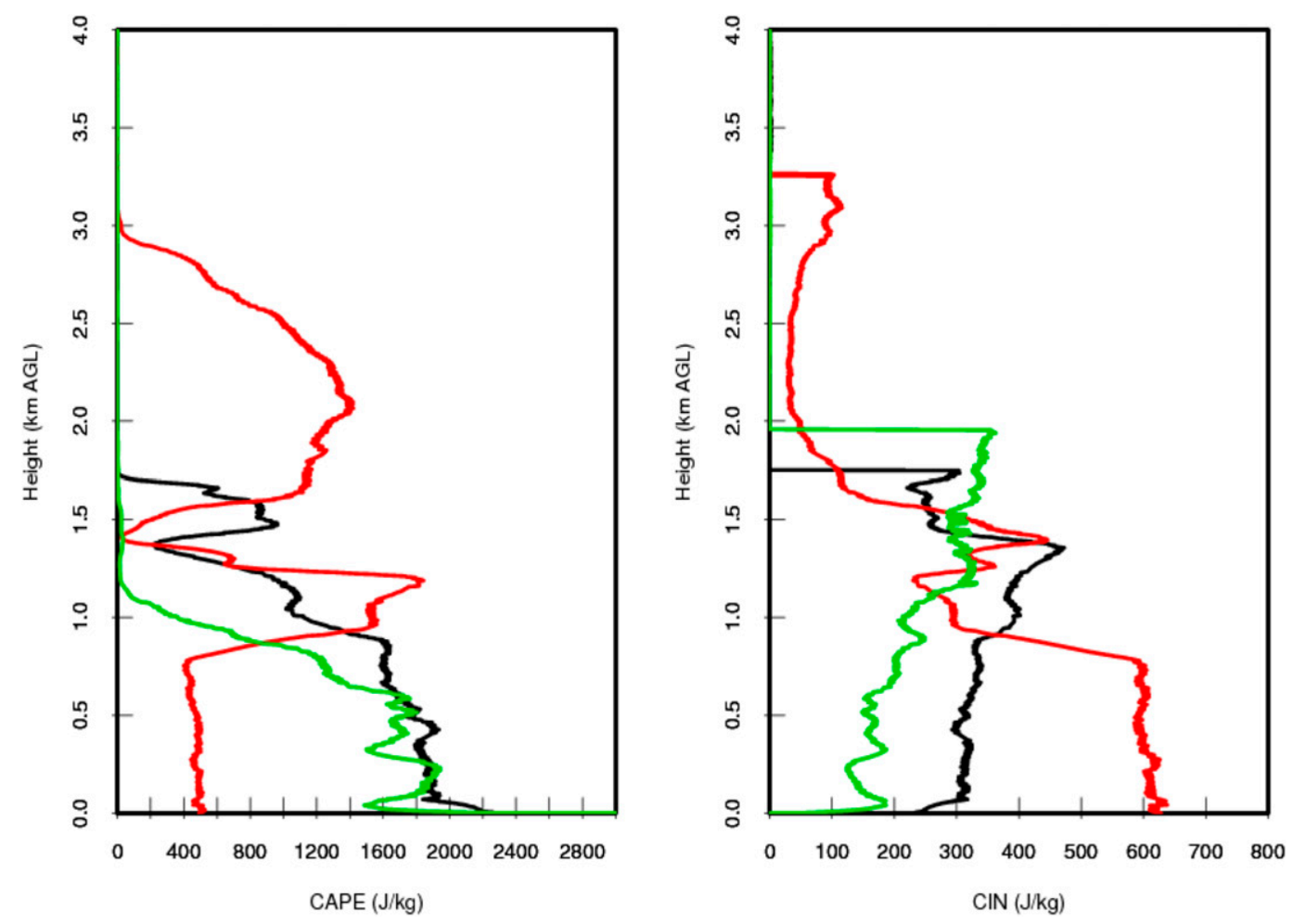

FIG. 14. (left) CAPE and (right) CIN for parcels originating at various heights for two daytime soundings launched at 1830 LST (black) 19 Jun prior to the bore passage and at 1200 LST (green) 20 Jun (i.e., the following afternoon). The red curve is from a sounding taken at 0002 LST 20 Jun during the passage of the bore.

soundings launched ahead of the bore and developing convection at Lamont, Oklahoma, and Hillsboro, Kansas. The predicted ascent raises a layer of high CAPE to heights between $600 \mathrm{~m}$ and $3 \mathrm{~km}$ and significantly reduces the CIN in this layer (Fig. 17). The end result is that after lifting, the layer aloft is quite susceptible to deep convection. While the Koch et al. (2008a) analysis examined surfacebased parcels, our depiction suggests that reduction of CIN in layers aloft associated with air near and above the axis of the NLLJ is likely to be more relevant for convection. This finding is also consistent with the composite (Fig. 3) suggesting that the most favorable layers for deep convection are at and above the NLLJ.

\section{Discussion and summary}

This study revealed that the most favorable conditions for deep convection over the Southern Great Plains occurred during the day within the convective boundary layer, in response to the diurnal cycle of solar heating. Conditions at night included the presence of separate low-level maxima in the westerly and southerly wind components, generally consistent with the evolution of the zonal and meridional winds found by Shapiro et al. (2016) and related work. At night, a weaker secondary maximum in CAPE was also observed near the height of southerly maxima in the NLLJ, while the enhanced westerly flow above this layer had low CIN and relatively high CAPE. Efforts to establish relative roles of ascent and differential advection in creating favorable CAPE and CIN conditions aloft in these layers is a focus of ongoing research (e.g., Rattray et al. 2018). We caution the reader that our composite may underestimate these favorable conditions for nocturnal convection, since recent work (e.g., Blake et al. 2017) suggests that the corridors of high-CAPE and low-CIN air aloft in association with the NLLJ can be quite narrow (e.g., $\sim 200 \mathrm{~km}$ ).

Since conditions are generally less favorable for deep convection during the night, we investigated the possibility that a positive feedback occurs between convection and the nocturnal environment. This positive feedback may explain the presence of the nocturnal maximum in convection. Such a positive feedback was proposed by Heideman and Fritsch (1988). Since Haghi et al. (2017) showed that bores are commonly triggered by convectively generated cold pools, we investigated bore lifting as a possible positive feedback. We determined that the ascent in 13 wave events was substantial (e.g., $\sim 500 \mathrm{~m}-1 \mathrm{~km}$ ) and extended throughout 


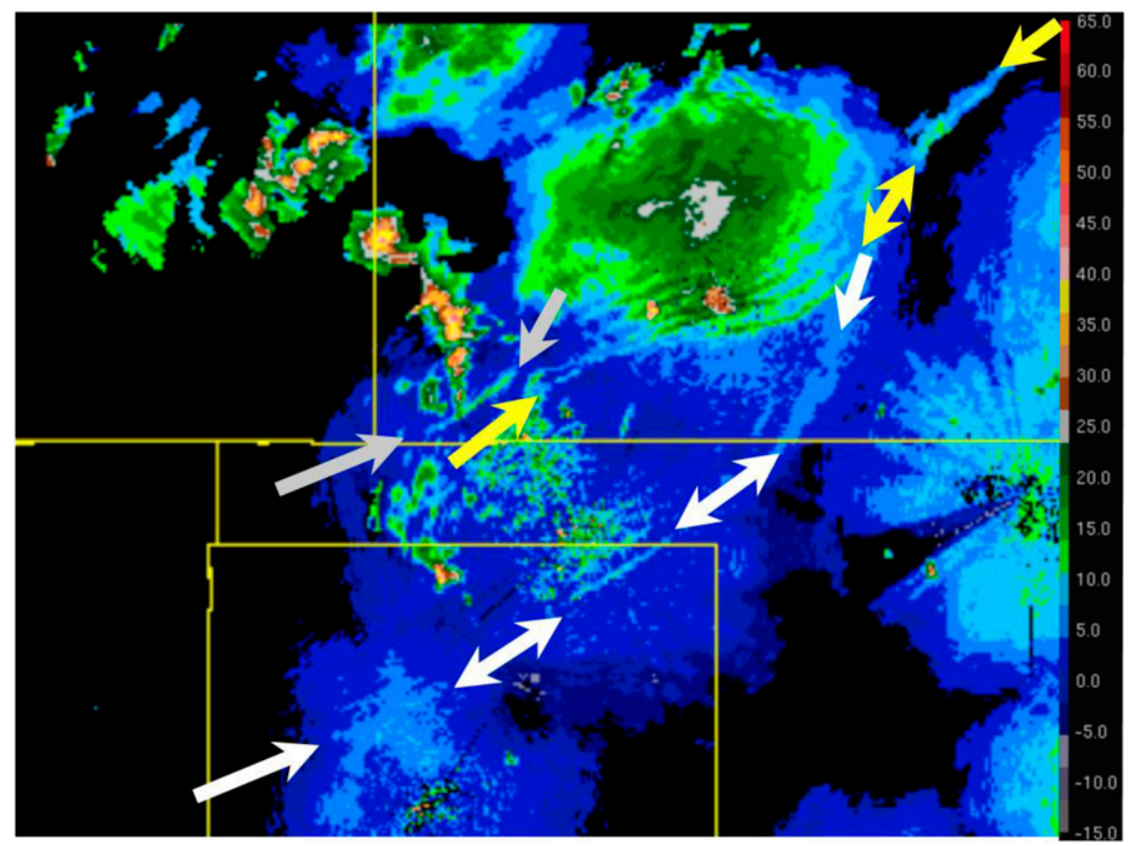

FIG. 15. Composite of radar reflectivity from the S-Pol and the operational network at 0130 LST 4 Jun 2002. The color scale for the radar reflectivity is shown on the right-hand side. The location of the leading edge of radar fine lines including undular bores are indicated with arrows. The differences in the color of the arrows are designed to help illustrate the sequential formation and propagation of the various fine lines.

the lower troposphere. This strong lifting extended into the favorable higher-CAPE and low-CIN layers at heights near and above the NLLJ. The structure of the waves, however, varied significantly from case to case and included both amplitudes that may have increased with height and the appearance of separate wave disturbances aloft within different vertical layers. These results are consistent both with the "indirect influence" of the bore on air above the stable nocturnal boundary (Koch et al. 2008b) and the presence of multiple wave ducts (Haghi et al. 2017). The dataset also suggests the likelihood of low-frequency gravity waves aloft, particularly for waves that were not initiated at the leading edge of a cold pool. Since low-frequency gravity waves will often have weaker lifting near the surface than a bore and may not induce a radar fine line, the frequency of these gravity waves and their role in reducing CIN may be underappreciated from casual observational analyses. The nature of these low-frequency disturbances aloft, their interplay with bores, and their impact on convective initiation and maintenance was difficult to address with the IHOP_2002 observations and is, therefore, an open question. We speculate, however, that the lifting of lower- and midtropospheric air ahead of the bores by low-frequency waves or indirect influence of the bores is likely to produce conditions more favorable to deep convection. Thus, such waves aloft ahead of the bores precondition the environment to enhance the likelihood of subsequent convective initiation/maintenance by the bores. The process is reminiscent of the interplay between lowand high-frequency gravity waves proposed by Fovell et al. (2006) as a mechanism for discretely propagating squall lines. We note that high-frequency gravity waves were also evident on these lifted layers, as in Fig. 7.

Radar observations analyzed from two bore events that were also studied by Koch and collaborators revealed that convection was initiated in association with bores, but was observed more frequently in the wake of the bores. Our analysis of admittedly sparse sounding data suggests that the upward displacements by the bores create conditions that are quite favorable for deep convection, with lifting reducing CIN in highCAPE vertical layers located between $\sim 500 \mathrm{~m}$ and $3 \mathrm{~km}$ in height. Our results show that the net upward displacements in the wake of the leading edge of bores lasted for several hours so that the destabilization could extend over areas $\geq 10^{4} \mathrm{~km}^{2}$. These results suggest that the attribution of bores to the initiation and/or maintenance of deep convection is difficult and may have been underestimated in the past. 

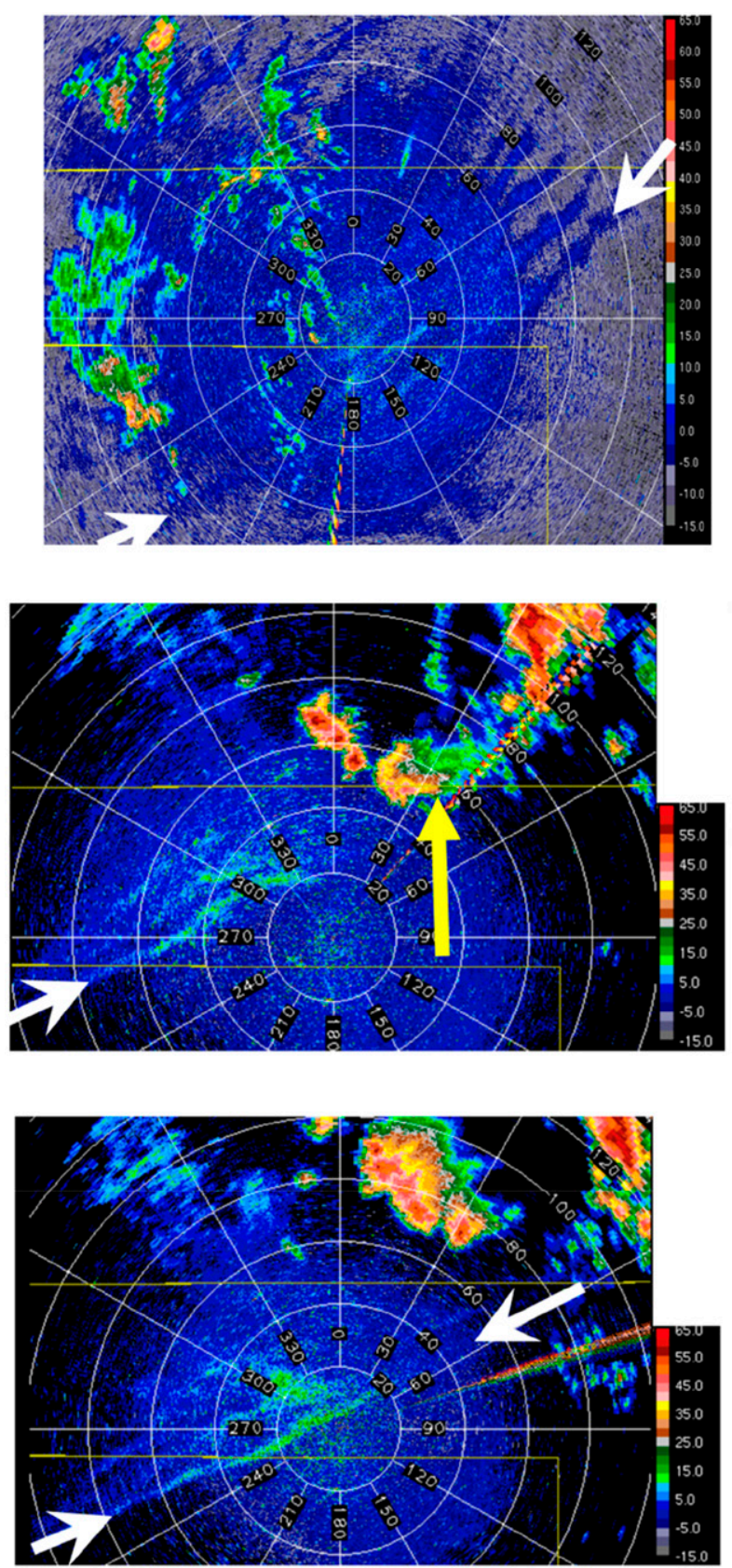

FIG. 16. Radar reflectivity from the S-Pol taken from a low-level surveillance scan during IHOP_2002 on 4 Jun 2002. The azimuth angles and radar range $(\mathrm{km})$ are indicated with the color scale are shown as in Fig. 8b. (a) 0130 LST with the first bore, (b) 0400 LST with the yellow arrow indicating new convection that formed along the leading edge of the bore, and (c) 0430 LST with the second bore.

One issue that is relevant to the destabilization in the wake of bores is whether the bore ascent is generally laminar or associated with significant mixing that can reduce CAPE as dry air aloft is mixed into convectively unstable layers. According to Haghi et al. (2017) and the observed bore longevity, the bores in this dataset should be generally (but not exclusively) laminar so that high CAPE will be maintained and CIN substantially reduced through ascent. Lifting and destabilization of large regions in the vicinity of convection is reminiscent of the proposal of gregarious tropical convection by Mapes (1993). In that study, the destabilization was driven by low-frequency gravity waves rather than bores triggered in partially blocked flow.

Since convectively generated bores and wave ascent create conditions more favorable for the continuation of nocturnal convection, we propose that this positive feedback will contribute to the nocturnal maximum in convection over the Great Plains in the presence of narrow corridors of high CAPE and low CIN in association with the NLLJ. Specifically, this feedback occurs as convective activity moves from the higher elevations to the west into a more favorable convective environment that supports partially blocked flows leading to long-lived bores. The ascent from these bores creates conditions more favorable for the initiation and/or maintenance of deep convection in the lower troposphere over substantial areas. Thus, as the convective instability transitions from surface based during the day to aloft with the NLLJ at night, the lifting induced by convection correspondingly evolves from surface-based gust fronts during the day to deep lifting by bores at night. Low-frequency gravity waves that will be generated by the buoyancy fields associated with deep convection will also reduce CIN. However, these events are likely present with both diurnal and nocturnal convection, as their initiation is not linked to a stable boundary layer. This corridor of warm air associated with the NLLJ may also be gently ascended, as discussed recently by Shapiro et al. (2018), further contributing to the initiation and maintenance of convective storms. For more details on convective initiation over this region, the reader is referred to Reif and Bluestein (2017).

We propose two specific scenarios for this positive feedback between bores and convection. In the first (Fig. 18a), which we will term as "bore maintained" or "bore induced" convection, the bore ascent is sufficient to directly maintain deep convection through raising unstable layers to their LFC. This scenario is observed in the later stages of Parker's (2008) and French and Parker's (2010) simulations and when convection is observed to be generated at leading edge of bores, as discussed in the previous section. However, we do note again that the relatively large distance $(\sim 10-100 \mathrm{~km})$ that can occur between the leading edge of the bore and the location of maximum ascent makes attribution difficult. 


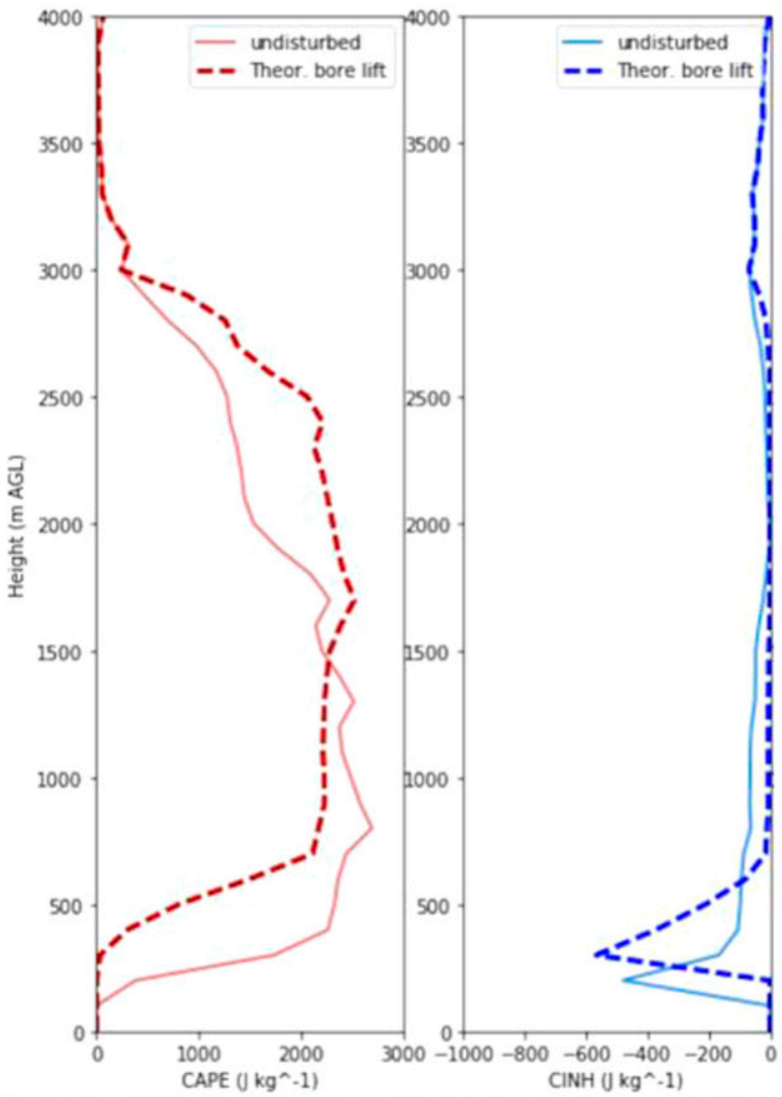

a

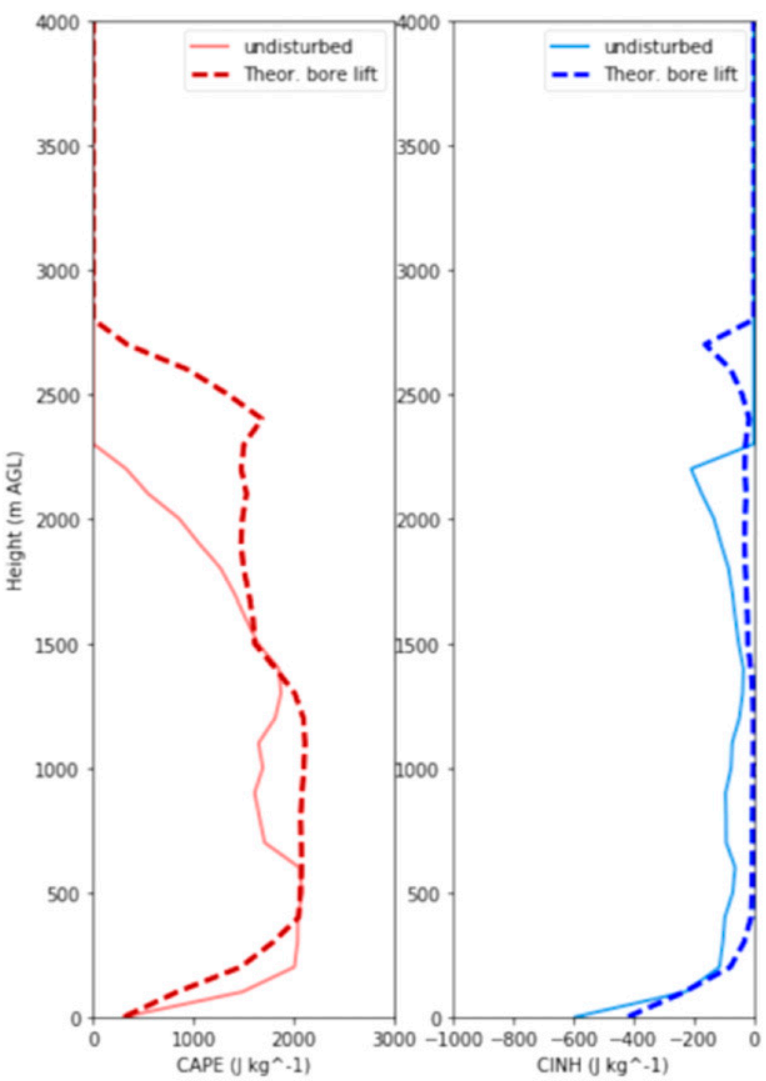

b

FIG. 17. Vertical profiles of CAPE and CIN from soundings and lifted profiles from ARM soundings taken on 4 Jun at Hillsboro, KS, at 0530 LST and at Lamont, OK, at 0529 LST. The technique is described by Haghi et al. (2017). The lifting technique is described in the text and is based upon estimations of the depth of the stable nocturnal boundary layer and the predicted bore amplitude.

The second scenario, which we will call bore-aided convection (Fig. 18b), occurs when lifting by the bores destabilizes the environment in the vicinity of convection, creating conditions that are more favorable for deep convection to be initiated or maintained by other processes. In the simulation by Blake et al. (2017), highCAPE and low-CIN air at and above the NLLJ is lifted by an undular bore and then brought to its LFC as this lifted air ascends over a lower-level cold pool. In Fig. 18b, both the bore and the cold pool play a role in maintaining the convective system, but the general concept of boreaided convection holds for convection triggered by other processes in the more favorable air mass left in the wake of the bore ascent. Given the large regions destabilized by bores and the tendency for bores to propagate ahead of active convective systems, such bore-aided convection is likely to be a common occurrence, and again, attribution is difficult. For example, in the previous section, bores were found to move into the system's inflow, and convection continued for many hours as cold pools and bores were repeatedly generated.
It is important to note that the bore-environment interaction is three-dimensional, since the wave trapping varies with the orientation of the cold pool through the so-called curvature term associated with the NLLJ. Hence, well-defined and easily detectable bores are likely to occur on the southern edge of the system where the curvature term is favorable, while deep vertically propagating waves or low-frequency gravity waves that are more difficult to detect are likely on the eastern flanks of systems (Blake et al. 2017). Given the difficulties in accurately representing the NLLJ and stable nocturnal boundary layer, together with the wide variations in bore structure, the complexity of the boreconvection interaction, the three-dimensional nature of this interaction, and the presence of wave responses aloft, it is not surprising that nocturnal convection remains a challenge for numerical modeling. This challenge is especially difficult in coarse-grid models, where convection must be parameterized.

The partially blocked flow observed in this dataset is not the only mode of convection that can occur over the 


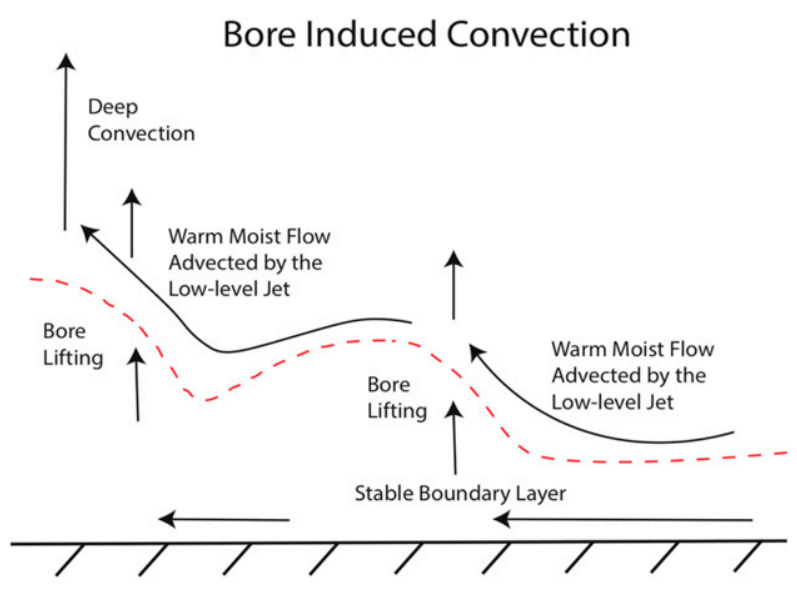

Bore Lifting Aiding the Maintenance of Convection

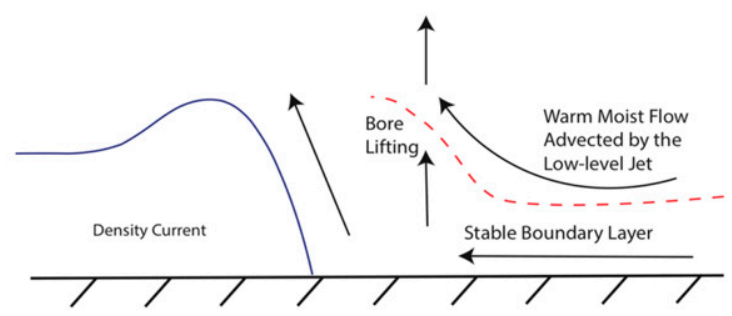

FIG. 18. Schematic of the potential role of bores in initiating or maintaining deep convection. (a) Bore-induced convection. (b) Bore-aided convection. The dashed line indicates the lifting of a layer by the bore. The blue line delineates the extent of the density current.

Great Plains. For example, the Parker (2008) and French and Parker (2010) simulations with rapidly moving cold pools also capture another mode of cold pool-environment interaction. The cold poolenvironment interactions in their simulations lie outside of the partially blocked regime for a significant percentage of their lifetimes due in large part to rapidly moving cold pools. The nocturnal bow echoes targeted during the Bow Echo and MCV Experiment (BAMEX; Davis et al. 2004) may fall into this category of nocturnal convective systems. Gust fronts overtaking bores in partially blocked flows are also a possible outcome that will impact the structure of the convective system.

An additional mode may have been observed in the recent PECAN field experiment (Geerts et al. 2017), as the observational focus included observing more strongly forced convective systems near the jet stream and well to the north of the IHOP_2002 domain. We hypothesize that the synoptic and frontal ascent and the enhanced low-level advection of warm, moist air in these strongly forced systems may preclude the presence of strong stability in the boundary layer and thus bore generation. Hence, in these instances, nocturnal convective systems may behave more similar to daytime systems in similar environments, perhaps providing limited insight into the causes of the nocturnal maximum in rainfall unless there is some diurnal variation in the synoptic forcing.

Acknowledgments. This research is generously supported by the National Science Foundation (NSF) under Grant AGS-1237404. The authors wish to thank those agencies (NSF, NOAA, NASA, DOE) that supported the IHOP_2002 project and individuals within IHOP_2002 that made this work possible, including Bill Brown (NCAR) for supporting the MAPR deployment and reprocessing some of the data to improve the figure quality; Belay Demoz (University of Maryland Baltimore County), who oversaw the deployment of the FM-CW radar; and David Carlson (formerly of NCAR), Steve Nelson (NSF), and Tammy Weckwerth (NCAR), who played critical roles in making the IHOP_2002 dream possible. We would also like to thank colleagues for valuable comments and discussions on this topic over the years, including Rich Rotunno (NCAR); Matt Parker (North Carolina State University); Ben Blake (NOAA/EMC); Joao Teixeira and Duane Waliser (NASA/JPL); Dale Durran (University of Washington); Stacey Hitchcock (Colorado State University); and especially Alan Shapiro, Larissa Reames, and Steven Cavallo (all of the University of Oklahoma's School of Meteorology). We would also like to thank the editor (Matt Parker), Kevin Knupp (University of Alabama in Huntsville), and two anonymous reviewers for improving this manuscript through the review process.

\section{REFERENCES}

Adams-Selin, R. D., and R. H. Johnson, 2013: Examination of gravity waves associated with the 13 March 2003 bow echo. Mon. Wea. Rev., 141, 3735-3756, https://doi.org/10.1175/ MWR-D-12-00343.1.

Ahijevych, D. A., C. A. Davis, R. E. Carbone, and J. D. Tuttle, 2004: Initiation of precipitation episodes relative to elevated terrain. J. Atmos. Sci., 61, 2763-2769, https://doi.org/10.1175/ JAS3307.1.

Arritt, R. W., T. D. Rink, M. Segal, D. P. Todey, C. A. Clark, M. J. Mitchell, and K. M. Labas, 1997: The Great Plains low-level jet during the warm season of 1993. Mon. Wea. Rev., 125, 2176-2192, https://doi.org/10.1175/1520-0493(1997)125<2176: TGPLLJ $>2.0 . \mathrm{CO} ; 2$.

Baines, P. G., 1984: A unified description of two-layer flow over topography. J. Fluid Mech., 146, 127-167, https://doi.org/ 10.1017/S0022112084001798. 
1995: Topographic Effects in Stratified Flows. Cambridge University Press, $482 \mathrm{pp}$.

— , and P. A. Davies, 1980: Laboratory studies of topographic effects in rotating and/or stratified fluids. Orographic effects in planetary flows, GARP Publ. 23, 233-239.

Blackadar, A. K., 1957: Boundary layer wind maxima and their significance for the growth of nocturnal inversions. Bull. Amer. Meteor. Soc., 38, 283-290, https://doi.org/10.1175/ 1520-0477-38.5.283.

Blake, B. T., D. B. Parsons, K. R. Haghi, and S. G. Castleberry, 2017: The structure, evolution, and dynamics of a nocturnal convective system simulated using the WRF-ARW Model. Mon. Wea. Rev., 145, 3179-3201, https://doi.org/10.1175/ MWR-D-16-0360.1

Bonner, W. D., 1968: Climatology of the low level jet. Mon. Wea. Rev., 96, 833-850, https://doi.org/10.1175/1520-0493(1968) 096<0833:COTLLJ>2.0.CO;2.

Bukovsky, M. S., and D. J. Karoly, 2009: Precipitation simulations using WRF as a nested regional climate model. J. Appl. Meteor. Climatol., 48, 2152-2159, https://doi.org/ 10.1175/2009JAMC2186.1.

Carbone, R. E., and J. D. Tuttle, 2008: Rainfall occurrence in the U.S. warm season: The diurnal cycle. J. Climate, 21, 4132-4146, https://doi.org/10.1175/2008JCLI2275.1.

, J. W. Conway, N. A. Crook, and M. W. Moncrieff, 1990: The generation and propagation of a nocturnal squall line. Part I: Observations and implications for mesoscale predictability. Mon. Wea. Rev., 118, 26-49, https://doi.org/10.1175/1520-0493(1990) $118<0026$ :TGAPOA $>2.0 . \mathrm{CO} ; 2$.

$\longrightarrow$ J. D. Tuttle, D. A. Ahijevych, and S. B. Trier, 2002: Inferences of predictability associated with warm season precipitation episodes. J. Atmos. Sci., 59, 2033-2056, https://doi.org/ 10.1175/1520-0469(2002)059<2033:IOPAWW>2.0.CO;2.

Carlson, T. N., S. G. Benjamin, G. S. Forbes, and Y.-F. Li, 1983: Elevated mixed layers in the regional severe storm environment: Conceptual model and case studies. Mon. Wea. Rev., 111, 1453-1474, https://doi.org/10.1175/1520-0493(1983)111<1453: EMLITR $>2.0 . \mathrm{CO} ; 2$

Clark, A. J., W. A. Gallus, and T.-C. Chen, 2007: Comparison of the diurnal precipitation cycle in convection-resolving and nonconvection-resolving mesoscale models. Mon. Wea. Rev., 135, 3456-3473, https://doi.org/10.1175/MWR3467.1.

Cohn, S. A., W. O. J. Brown, C. L. Martin, M. E. Susedik, G. D. Maclean, and D. B. Parsons, 2001: Clear air boundary layer spaced antenna wind measurement with the Multiple Antenna Profiler (MAPR). Ann. Geophys., 19, 845-854, https://doi.org/ 10.5194/angeo-19-845-2001.

Coleman, T. A., and K. R. Knupp, 2011: Radiometer and profiler analysis of the effects of a bore and a solitary wave on the stability of the nocturnal boundary layer. Mon. Wea. Rev., 139, 211-223, https://doi.org/10.1175/2010MWR3376.1.

— - — , and D. E. Herzmann, 2010: An undular bore and gravity waves illustrated by dramatic time-lapse photography. J. Atmos. Oceanic Technol., 27, 1355-1361, https://doi.org/ 10.1175/2010JTECHA1472.1.

Colman, B. R., 1990a: Thunderstorms above frontal surfaces in environments without positive CAPE. Part I: A climatology. Mon. Wea. Rev., 118, 1103-1122, https://doi.org/10.1175/15200493(1990)118<1103:TAFSIE > 2.0.CO;2.

, 1990b: Thunderstorms above frontal surfaces in environments without positive CAPE. Part II: Organization and instability mechanisms. Mon. Wea. Rev., 118, 1123-1144, https://doi.org/ 10.1175/1520-0493(1990)118<1123:TAFSIE > 2.0.CO;2.
Crook, N. A., 1986: The effect of ambient stratification and moisture on the motion of atmospheric undular bores. J. Atmos. Sci., 43, 171-181, https://doi.org/10.1175/1520-0469(1986) $043<0171$ :TEOASA $>2.0$. CO 2 .

_ R. E. Carbone, M. W. Moncrieff, and J. W. Conway, 1990: The generation and propagation of a nocturnal squall line. Part II: Numerical simulations. Mon. Wea. Rev., 118, 50-65, https:// doi.org/10.1175/1520-0493(1990)118<0050:TGAPOA > 2.0.CO;2.

Curtis, R. C., and H. A. Panofsky, 1958: The relationship between large-scale vertical motion and weather in summer. Bull. Amer. Meteor. Soc., 39, 521-531, https://doi.org/10.1175/15200477-39.10.521.

Dai, A., F. Giorgi, and K. E. Trenberth, 1999: Observed and modelsimulated diurnal cycles of precipitation over the contiguous United States. J. Geophys. Res., 104, 6377-6402, https://doi.org/ 10.1029/98JD02720.

Davis, C. A., K. W. Manning, R. E. Carbone, S. B. Trier, and J. D. Tuttle, 2003: Coherence of warm-season continental rainfall in numerical weather prediction models. Mon. Wea. Rev., 131, 2667-2679, https://doi.org/10.1175/1520-0493(2003)131<2667: COWCRI $>2.0 . \mathrm{CO} ; 2$

- and Coauthors, 2004: The Bow Echo and MCV Experiment: Observations and opportunities. Bull. Amer. Meteor. Soc., 85, 1075-1094, https://doi.org/10.1175/BAMS-85-8-1075.

Easterling, D. R., and P. J. Robinson, 1985: The diurnal variation of thunderstorm activity in the United States. J. Climate Appl. Meteor., 24, 1048-1058, https://doi.org/10.1175/1520-0450(1985) 024<1048:TDVOTA $>2.0$. CO;2.

Fovell, R. G., 2002: Upstream influence of numerically simulated squall-line storms. Quart. J. Roy. Meteor. Soc., 128, 893-912, https://doi.org/10.1256/0035900021643737.

_ , G. L. Mullendore, and S.-H. Kim, 2006: Discrete propagation in numerically simulated nocturnal squall lines. Mon. Wea. Rev., 134, 3735-3752, https://doi.org/10.1175/MWR3268.1.

French, J., and M. D. Parker, 2010: The response of simulated nocturnal convective systems to a developing low-level jet. J. Atmos. Sci., 67, 3384-3408, https://doi.org/10.1175/2010JAS3329.1.

Geerts, B., and Q. Miao, 2005: The use of millimeter Doppler radar echoes to estimate vertical air velocities in the fair-weather convective boundary layer. J. Atmos. Oceanic Technol., 22, 225-246, https://doi.org/10.1175/JTECH1699.1.

_ , and Coauthors, 2017: The 2015 Plains Elevated Convection at Night (PECAN) field project. Bull. Amer. Meteor. Soc., 98 , 767-786, https://doi.org/10.1175/BAMS-D-15-00257.1.

Haghi, K. R., D. B. Parsons, and A. Shapiro, 2017: Bores observed during IHOP_2002: The relationship of bores to the nocturnal environment. Mon. Wea. Rev., 145, 3929-3946, https://doi.org/ 10.1175/MWR-D-16-0415.1.

Hartung, D. C., J. A. Otkin, J. E. Martin, and D. Turner, 2010: The life cycle of an undular bore and its interaction with a shallow, intense cold front. Mon. Wea. Rev., 138, 886-908, https://doi.org/ 10.1175/2009MWR3028.1.

Heideman, K. F., and J. M. Fritsch, 1988: Forcing mechanisms and other characteristics of significant summertime convection. Wea. Forecasting, 3, 115-130, https://doi.org/10.1175/15200434(1988)003<0115:FMAOCO > 2.0.CO;2.

Hering, W. S., and T. R. Borden Jr., 1962: Diurnal variations in the summer wind field over the central United States. J. Atmos. Sci., 19, 81-86, https://doi.org/10.1175/1520-0469(1962)019<0081: DVITSW $>2.0 . \mathrm{CO} ; 2$.

Holton, J. R., 1967: The diurnal boundary layer wind oscillation over sloping terrain. Tellus, 19A, 199-205, https://doi.org/ 10.1111/j.2153-3490.1967.tb01473.x. 
Houghton, D. D., and A. Kasahara, 1968: Nonlinear shallow fluid flow over an isolated ridge. Commun. Pure Appl. Math., 21, 1-23, https://doi.org/10.1002/cpa.3160210103.

Karyampudi, V. M., S. E. Koch, C. Chen, J. W. Rottman, and M. L. Kaplan, 1995: The influence of the Rocky Mountains on the 13-14 April 1986 severe weather outbreak. Part II: Evolution of a prefrontal bore and its role in triggering a squall line. Mon. Wea. Rev., 123, 1423-1446, https://doi.org/10.1175/1520-0493(1995) 123<1423:TIOTRM $>2.0 . \mathrm{CO} ; 2$.

Kincer, J. B., 1916: Daytime and nighttime precipitation and their economic significance. Mon. Wea. Rev., 44, 628-633, https:// doi.org/10.1175/1520-0493(1916)44<628:DANPAT>2.0.CO;2.

Knupp, K., 2006: Observational analysis of a gust front to bore to solitary wave transition within an evolving nocturnal boundary layer. J. Atmos. Sci., 63, 2016-2035, https://doi.org/10.1175/ JAS3731.1.

— R. Wade, A. W. Lyza, and S. M. Wingo, 2016: Comparison of estimates of vertical motion from vertically-pointing lidar and radar within gust fronts, bores and low-level gravity waves. 18th Symp. on Meteorological Observation and Instrumentation, New Orleans, LA, Amer. Meteor. Soc., 5.2, https://ams.confex.com/ ams/96Annual/webprogram/Paper290321.html.

Koch, S. E., and W. L. Clark, 1999: A nonclassical cold front observed during COPS-91: Frontal structure and the process of severe storm initiation. J. Atmos. Sci., 56, 2862-2890, https://doi.org/10.1175/1520-0469(1999)056<2862: ANCFOD $>2.0 . \mathrm{CO} ; 2$.

, P. B. Dorian, R. Ferrare, S. H. Melfi, W. C. Skillman, and D. Whiteman, 1991: Structure of an internal bore and dissipating gravity current as revealed by Raman lidar. Mon. Wea. Rev., 119, 857-887, https://doi.org/10.1175/1520-0493(1991) $119<0857:$ SOAIBA $>2.0$. CO 2 .

—, C. Flamant, J. W. Wilson, B. M. Gentry, and B. D. Jamison, 2008a: An atmospheric soliton observed with Doppler radar, differential absorption lidar, and a molecular Doppler lidar. J. Atmos. Oceanic Technol., 25, 1267-1287, https://doi.org/ 10.1175/2007JTECHA951.1.

, W. Feltz, F. Fabry, M. Pagowski, B. Geerts, K. M. Bedka, D. O. Miller, and J. W. Wilson, 2008b: Turbulent mixing processes in atmospheric bores and solitary waves deduced from profiling systems and numerical simulation. Mon. Wea. Rev., 136, 13731400, https://doi.org/10.1175/2007MWR2252.1.

Lane, T. P., and M. R. Reeder, 2001: Convectively generated gravity waves and their effect on the cloud environment. J. Atmos. Sci., 58, 2427-2440, https://doi.org/10.1175/15200469(2001)058<2427:CGGWAT>2.0.CO;2.

Li, Y., and R. B. Smith, 2010: The detection and significance of diurnal pressure and potential vorticity anomalies east of the Rockies. J. Atmos. Sci., 67, 2734-2751, https://doi.org/10.1175/ 2010JAS3423.1.

Locatelli, J. D., M. T. Stoelinga, and P. V. Hobbs, 2002: A new look at the super outbreak of tornadoes on 3-4 April 1974. Bull. Amer. Meteor. Soc., 79, 1633-1651, https://doi.org/ 10.1175/1520-0493(2002)130<1633:ANLATS > 2.0.CO;2.

Long, R. R., 1954: Some aspects of the flow of stratified fluids: II. Experiments with a two-fluid system. Tellus, 6A, 97-115, https://doi.org/10.1111/j.2153-3490.1954.tb01100.x.

Maddox, R. A., 1980: Mesoscale convective complexes. Bull. Amer. Meteor. Soc., 61, 1374-1387, https://doi.org/10.1175/ 1520-0477(1980)061<1374:MCC>2.0.CO;2.

_ C. F. Chappell, and L. R. Hoxit, 1979: Synoptic and meso- $\alpha$ scale aspects of flash flood events. Bull. Amer. Meteor. Soc., 60, 115-123, https://doi.org/10.1175/1520-0477-60.2.115.
Mapes, B. E., 1993: Gregarious tropical convection. J. Atmos. Sci., 50, 2026-2037, https://doi.org/10.1175/1520-0469(1993)050<2026: GTC $>2.0 . C O ; 2$.

Marsham, J. H., S. B. Trier, T. M. Weckwerth, and J. W. Wilson, 2011: Observations of elevated convection initiation leading to a surface-based squall line during 13 June IHOP_2002. Mon. Wea. Rev., 139, 247-271, https://doi.org/10.1175/2010MWR3422.1.

Martin, E. R., and R. H. Johnson, 2008: An observational and modeling study of an atmospheric internal bore during NAME 2004. Mon. Wea. Rev., 136, 4150-4167, https://doi.org/10.1175/ 2008MWR2486.1.

Mather, J. H., and J. W. Voyles, 2013: The ARM Climate Research Facility: A review of structure and capabilities. Bull. Amer. Meteor. Soc., 94, 377-392, https://doi.org/10.1175/BAMS-D11-00218.1.

Means, L. L., 1952: On thunderstorm forecasting in the central United States. Mon. Wea. Rev., 80, 165-189, https://doi.org/ 10.1175/1520-0493(1952)080<0165:OTFITC $>2.0$. CO;2.

Nicholls, M. E., R. A. Pielke, and W. R. Cotton, 1991: Thermally forced gravity waves in an atmosphere at rest. J. Atmos. Sci., 48, 1869-1884, https://doi.org/10.1175/1520-0469(1991)048<1869: TFGWIA $>2.0 . \mathrm{CO} ; 2$.

Paegle, J., 1978: A linearized analysis of diurnal boundary layer convergence over the topography of the United States. Mon. Wea. Rev., 106, 492-502, https://doi.org/10.1175/1520-0493(1978) $106<0492$ :ALAODB $>2.0 . C O ; 2$.

Pandya, R. E., and D. R. Durran, 1996: The influence of convectively generated thermal forcing on the mesoscale circulation around squall lines. J. Atmos. Sci., 53, 2924-2951, https:// doi.org/10.1175/1520-0469(1996)053<2924:TIOCGT>2.0.CO;2. D. Durran, and C. Bretherton, 1993: Comments on "Thermally forced gravity waves in an atmosphere at rest." J. Atmos. Sci., 50, 4097-4101, https://doi.org/10.1175/15200469(1993)050<4097:COFGWI > 2.0.CO;2.

Parker, M. D., 2008: Response of simulated squall lines to low-level cooling. J. Atmos. Sci., 65, 1323-1341, https://doi.org/10.1175/ 2007JAS2507.1.

- , and D. Ahijevych, 2007: Convective episodes in the eastcentral United States. Mon. Wea. Rev., 135, 3707-3727, https:// doi.org/10.1175/2007MWR2098.1.

Parsons, D. B., M. A. Shapiro, R. M. Hardesty, R. J. Zamora, and J. M. Intrieri, 1991: The finescale structure of a west Texas dryline. Mon. Wea. Rev., 119, 1242-1258, https://doi.org/ 10.1175/1520-0493(1991)119<1242:TFSOAW > 2.0.CO;2. , and Coauthors, 1994: The Integrated Sounding System: Description and preliminary observations from TOGA COARE. Bull. Amer. Meteor. Soc., 75, 553-568, https://doi.org/10.1175/ 1520-0477(1994)075<0553:TISSDA > 2.0.CO;2.

Pitchford, K. L., and J. London, 1962: The low-level jet as related to nocturnal thunderstorms over Midwest United States. J. Appl. Meteor., 1, 43-47, https://doi.org/10.1175/1520-0450(1962)001<0043: TLLJAR $>2.0 . \mathrm{CO} ; 2$.

Pritchard, M. S., M. W. Moncrieff, and R. C. J. Somerville, 2011: Orogenic propagating precipitation systems over the United States in a global climate model with embedded explicit convection. J. Atmos. Sci., 68, 1821-1840, https://doi.org/10.1175/ 2011JAS3699.1.

Pu, B., and R. E. Dickinson, 2014: Diurnal spatial variability of Great Plains summer precipitation related to the dynamics of the low-level jet. J. Atmos. Sci., 71, 1807-1817, https://doi.org/ 10.1175/JAS-D-13-0243.1.

Rattray, C., D. B. Parsons, and A. Shapiro, 2018: Low-level jet making the atmosphere unstable again. 17th Annual Student Conf., 
Austin, TX, Amer. Meteor. Soc., S168, https://ams.confex.com/ ams/98Annual/meetingapp.cgi/Paper/338448.

Reif, D. W., and H. B. Bluestein, 2017: A 20-year climatology of nocturnal convection initiation over the central and southern Great Plains during the warm season. Mon. Wea. Rev., 145, 1615-1639, https://doi.org/10.1175/MWR-D-16-0340.1.

Riddle, A. C., W. M. Angevine, W. L. Ecklund, E. Miller, D. Parsons, D. A. Carter, and K. S. Gage, 1996: Wind-profiler and rawinsonde observations compared at ISS sites during TOGA COARE. Contrib. Atmos. Phys., 69, 49-62.

Rottman, J. W., and J. E. Simpson, 1989: The formation of internal bores in the atmosphere: A laboratory model. Quart. J. Roy. Meteor. Soc., 115, 941-963, https://doi.org/10.1002/ qj.49711548809.

Rotunno, R., J. B. Klemp, and M. L. Weisman, 1988: A theory for strong, long-lived squall lines. J. Atmos. Sci., 45, 463-485, https://doi.org/10.1175/1520-0469(1988)045<0463: ATFSLL $>2.0 . \mathrm{CO} ; 2$.

Scorer, R. S., 1949: Theory of waves in the lee of mountains. Quart. J. Roy. Meteor. Soc., 75, 41-56, https://doi.org/10.1002/ qj. 49707532308 .

Shapiro, A., E. Fedorovich, and S. Rahimi, 2016: A unified theory for the Great Plains nocturnal low-level jet. J. Atmos. Sci., 73, 3037-3057, https://doi.org/10.1175/JAS-D-15-0307.1.

- — - and J. B. Gebauer, 2018: Mesoscale ascent in nocturnal low- level jets. J. Atmos. Sci., 75, 1403-1427, https://doi.org/ 10.1175/JAS-D-17-0279.1.

Stankov, B. B., E. E. Gossard, B. L. Weber, R. J. Lataitis, A. B. White, D. E. Wolfe, D. C. Welsh, and R. G. Strauch, 2003: Humidity gradient profiles from wind profiling radars using the NOAA/ETL Advanced Signal Processing System (SPS). J. Atmos. Oceanic Technol., 20, 3-22, https://doi.org/10.1175/ 1520-0426(2003)020<0003:HGPFWP > 2.0.CO;2.

Stephan, C., M. J. Alexander, and J. H. Richter, 2016: Characteristics of gravity waves from convection and implications for their parameterization in global circulation models. J. Atmos. Sci., 73, 2729-2742, https://doi.org/10.1175/JAS-D-15-0303.1.

Stokes, G. M., and S. E. Schwartz, 1994: The Atmospheric Radiation Measurement (ARM) Program: Programmatic background and design of the cloud and radiation test bed. Bull. Amer. Meteor. Soc., 75, 1201-1222, https://doi.org/10.1175/ 1520-0477(1994)075<1201:TARMPP > 2.0.CO;2.

Sun, W.-Y., and Y. Ogura, 1979: Boundary-layer forcing as a possible trigger to a squall- line formation. J. Atmos. Sci., 36, 235-254, https://doi.org/10.1175/1520-0469(1979)036<0235: BLFAAP $>2.0 . \mathrm{CO} ; 2$.

Surcel, M., M. Berenguer, and I. Zawadzki, 2010: The diurnal cycle of precipitation from continental radar mosaics and numerical weather prediction models. Part I: Methodology and seasonal comparison. Mon. Wea. Rev., 138, 3084-3106, https://doi.org/ 10.1175/2010MWR3125.1.
Tanamachi, R. L., W. F. Feltz, and M. Xue, 2008: Observations and numerical simulation of upper boundary layer rapid drying and moistening events during the International $\mathrm{H}_{2} \mathrm{O}$ Project (IHOP_2002). Mon. Wea. Rev., 136, 3106-3120, https://doi.org/ 10.1175/2008MWR2204.1.

Trier, S. B., and D. B. Parsons, 1993: Evolution of environmental conditions preceding the development of a nocturnal mesoscale convective complex. Mon. Wea. Rev., 121, 1078-1098, https://doi.org/10.1175/1520-0493(1993)121<1078: EOECPT $>2.0 . \mathrm{CO} ; 2$.

Tripoli, G., and W. R. Cotton, 1989a: Numerical study of an observed orogenic mesoscale convective system. Part 1: Simulated genesis and comparison with observations. Mon. Wea. Rev., 117, 273-304, https://doi.org/10.1175/1520-0493(1989) $117<0273$ :NSOAOO $>2.0 . \mathrm{CO} ; 2$.

$\longrightarrow$, and $ـ 1989 \mathrm{~b}$ : Numerical study of an observed orogenic mesoscale convective system. Part 2: Analysis of governing dynamics. Mon. Wea. Rev., 117, 305-328, https://doi.org/ 10.1175/1520-0493(1989)117<0305:NSOAOO >2.0.CO;2.

Tsuda, T., M. Miyamoto, and J.-I. Furumoto, 2001: Estimation of a humidity profile using turbulence echo characteristics. J. Atmos. Oceanic Technol., 18, 1214-1222, https://doi.org/ 10.1175/1520-0426(2001)018<1214:EOAHPU > 2.0.CO;2.

Tuttle, J. D., and C. A. Davis, 2006: Corridors of warm season precipitation in the central United States. Mon. Wea. Rev., 134, 2297-2317, https://doi.org/10.1175/MWR3188.1.

Wakimoto, R. M., and D. E. Kingsmill, 1995: Structure of an atmospheric undular bore generated from colliding boundaries during CAPE. Mon. Wea. Rev., 123, 1374-1393, https://doi.org/ 10.1175/1520-0493(1995)123<1374:SOAAUB > 2.0.CO;2.

Wallace, J. M., 1975: Diurnal variations in precipitation and thunderstorm frequency over the conterminous United States. Mon. Wea. Rev., 103, 406-419, https://doi.org/10.1175/15200493(1975)103<0406:DVIPAT>2.0.CO;2.

_ , and P. V. Hobbs, 1977: Atmospheric Science: An Introductory Survey. Academic Press, 467 pp.

Weckwerth, T. M., and D. B. Parsons, 2006: A review of convection initiation and motivation for IHOP_2002. Mon. Wea. Rev., 134, 5-22, https://doi.org/10.1175/MWR3067.1.

, and Coauthors, 2004: An overview of the International $\mathrm{H}_{2} \mathrm{O}$ Project (IHOP_2002) and some preliminary highlights. Bull. Amer. Meteor. Soc., 85, 253-278, https://doi.org/10.1175/ BAMS-85-2-253.

Whiteman, D. N., and Coauthors, 2006: Raman lidar measurements during the International $\mathrm{H} 2 \mathrm{O}$ Project. Part I: Instrumentation and analysis techniques. J. Atmos. Oceanic Technol., 23, 157-169, https://doi.org/10.1175/JTECH1838.1.

Wilson, J. W., and R. D. Roberts, 2006: Summary of convective storm initiation and evolution during IHOP: Observational and modeling perspective. Mon. Wea. Rev., 134, 23-47, https:// doi.org/10.1175/MWR3069.1. 